\title{
The neotypification of Frontonia vernalis (Ehrenberg, 1833) Ehrenberg, 1838 and the description of Frontonia paravernalis sp. nov. trigger a critical revision of frontoniid systematics
}

\author{
Valentina Serra ${ }^{1 *}$ (D), Aldo D'Alessandro ${ }^{1,2}$, Venkatamahesh Nitla', Leandro Gammuto', Letizia Modeo ${ }^{1,3,4}$, \\ Giulio Petroni ${ }^{1,3,4^{*}}$ and Sergei I. Fokin ${ }^{1,5,6}$
}

\begin{abstract}
Background: Among Oligohymenophorea (Ciliophora, Alveolata) the subclass Peniculia stands as one of the most well-known groups. Frontonia is the largest genus of Peniculia, and its representatives are spread in any type of water bodies as well as in soil. At a first glance, Frontonia species exhibit an overall similar morphology, and form a well-recognizable taxon of ciliates. Despite the general morphological homogeneity, the phylogenetic analysis based on the $18 \mathrm{~S}$ rDNA sequencing showed that Frontonia is a non-monophyletic group. The systematics of this genus should be deeply reviewed, although additional issues complicate the task solving. First, type species of the genus is not yet clearly established, and no type material is available. In this context, the situation of $F$. vernalis, one of the first Frontonia ever described, is somehow puzzled: the description of this ciliate made by Ehrenberg (in 1833 and 1838) contains several inaccuracies and subsequent misidentifications by other authors occurred. Moreover, the $18 \mathrm{~S}$ rDNA sequence of a putative $F$. vernalis is available on GenBank, but no morphological description of the correspondent specimens is provided; thus, in our opinion, it should be only prudently associated with $F$. vernalis or at least indicated as "F. vernalis".
\end{abstract}

Results: In the present work, we provide the neotypification of $F$. vernalis newly found in Italy, presenting its multidisciplinary description and its neotype material. Similarly, we describe a novel species bearing Chlorella-like endosymbionts, Frontonia paravernalis sp. nov., retrieved in two far distant locations (Italy, Russia). A critical discussion on the status of Frontonia taxonomy and phylogeny is also presented, based on the 18S rDNA sequencing of both these two newly collected species and other 14 frontoniids isolated in different parts of the world. Finally, in the present study F. leucas was neotypified and proposed as the type species of the genus.

(Continued on next page)

\footnotetext{
* Correspondence: valentina.serra@biologia.unipi.it; giulio.petroni@unipi.it

The article is dedicated to the memory of Prof. Wilhelm Foissner (1948-

2020), an outstanding ciliate taxonomist and the best expert in biodiversity

of protist.

'Department of Biology, University of Pisa, Pisa, Italy

Full list of author information is available at the end of the article
}

C C The Author(s). 2021 Open Access This article is licensed under a Creative Commons Attribution 4.0 International License, which permits use, sharing, adaptation, distribution and reproduction in any medium or format, as long as you give appropriate credit to the original author(s) and the source, provide a link to the Creative Commons licence, and indicate if changes were made. The images or other third party material in this article are included in the article's Creative Commons licence, unless indicated otherwise in a credit line to the material. If material is not included in the article's Creative Commons licence and your intended use is not permitted by statutory regulation or exceeds the permitted use, you will need to obtain permission directly from the copyright holder. To view a copy of this licence, visit http://creativecommons.org/licenses/by/4.0/. The Creative Commons Public Domain Dedication waiver (http://creativecommons.org/publicdomain/zero/1.0/) applies to the data made available in this article, unless otherwise stated in a credit line to the data. 
(Continued from previous page)

Conclusions: Green frontoniids form a monophyletic clade of freshwater organisms characterized by having a single contractile vacuole and bearing intracytoplasmatic Chlorella-like symbionts. With the neotypification of $F$. vernalis and F. leucas a fundamental step in Frontonia systematics was taken, and the bases for further taxonomic studies were laid.

Keywords: Peniculia, Phylogeny, Green frontoniids, Frontonia vernalis, Frontonia leucas, Neotypification, Taxonomy

\section{Background}

Among Oligohymenophorea (Ciliophora, Alveolata) the subclass Peniculia is one of the most well-known and, in some respects, actively studied group of ciliates. Some peniculines, such as members of the Paramecium genus, serve as useful model organisms in protistology and other biological disciplines since time. Moreover, Peniculia is one of the most common group of ciliates, retrieved in many and different biotopes, in particular highly represented by Frontonia and Paramecium [1-17]. Frontonia is the largest genus of Peniculia, comprising, according to literature data, more than 40 species. However, only some of them are relatively common [3, 7, 11, 15, 16, 18-25]. Frontonia representatives are widely spread in any type of water bodies (freshwater, brackish water and marine) as well as in soil [7].

At a first glance, Frontonia members exhibit an overall similar morphology, forming a well-recognizable group of ciliates. Shared characters are: i) a more anterior location of cytostome with respect to its position in Paramecium; ii) the bucco-kinetal type of stomatogenesis, with a distinctive set of oral membranelles (so-called "oligohymenium") consisting in three peniculi on the left side of the buccal cavity plus a paroral membrane on the right buccal margin; iii) a somatic ciliature uniformly organized (except for some vestibular and postoral kineties) with distinctive pre- and postoral sutures; and iv) a typical kind of extrusome (trichocyst, according to their similarity with trichocyts of Paramecium) inserted in the cell cortex. At the same time, other morphological features appear strongly variable within the group (e.g., number and structure of contractile vacuoles, composition of buccal ciliature, micronuclei number and type, and cell size/shape). Despite the general morphological homogeneity, the phylogenetic analysis based on $18 \mathrm{~S}$ rDNA sequences showed that Frontonia is a nonmonophyletic group [26, 27]. This result has been confirmed using different sets of frontoniids and by different research groups (e.g., $[11,15,16,28])$. Thus, it can be hypothesised that the "frontoniid" morphotype could be the result of a sum of plesiomorphies retained in different lineages of peniculines. This situation caused the present paraphyly of the genus.

It is our opinion that the systematics of this genus should be deeply reviewed, although we realized that some issues complicate even more the task. First of all, the type species of the genus is not yet clearly established, and at present no type material is available. Indeed, Frontonia leucas (Ehrenberg, 1833) Ehrenberg, 1838, one of the first described Frontonia species which could be eligible to this role, actually consists of a set of different species, morphologically close to each other [3, 9]. In addition, also the other species described by Ehrenberg in 1833, Frontonia vernalis (Ehrenberg, 1833) Ehrenberg, 1838, presents a somehow puzzled situation. Actually, it was described by Ehrenberg as a freshwater species, 211-254 $\mu \mathrm{m}$ long, bearing Chlorella-like cytoplasmic endosymbionts, and carrying two contractile vacuoles (CVs) (Fig. 1) [29, 30]. Unfortunately, subsequent misidentifications by other authors occurred [17]: for instance, F. vernalis sensu Bullington [31] cannot be considered coincident with $F$. vernalis sensu Ehrenberg, because Bullington described a brackish water Frontonia species without Chlorella-like symbionts, morphologically closer to the F. fusca described by Quennerstedt [32] and recently redescribed by Fokin [10].

Additionally, molecular data regarding $F$. vernalis are somehow confusing as well. As for many other Frontonia's $18 \mathrm{~S}$ rDNA sequences present in on-line databases, the sequence of a putative $F$. vernalis available on GenBank (accession number U97110) is not linked to any morphological description. This sequence is the only one available for the species and was deposited by Hirt and colleagues in 1997, not supported by any publication. In fact, this ciliate isolated in England (UK) has never been morphologically described. Moreover, it is known that Hirt and colleagues worked with freshwater frontoniids hosting Chlorella-like cytoplasmic symbionts (e.g., [33-35]) detected in a small productive pond (Priest Pot, Like District, Cumbria, England, UK), although these organisms, according to few pictures presented in their publications, probably do not match the original morphotype of $F$. vernalis for which Ehrenberg mentioned the presence of two CVs (Fig. 1). In this context, we suggest that the sequence U97110 should not be reliably associated with $F$. vernalis, since a description based on a multidisciplinary study approach [16, 36, 37] of the corresponding organism is lacking.

It is worth noting that, to date, nobody has succeeded to find a ciliate corresponding to the Ehrenberg's F. vernalis (i.e., showing two CVs), although "green" Frontonia 


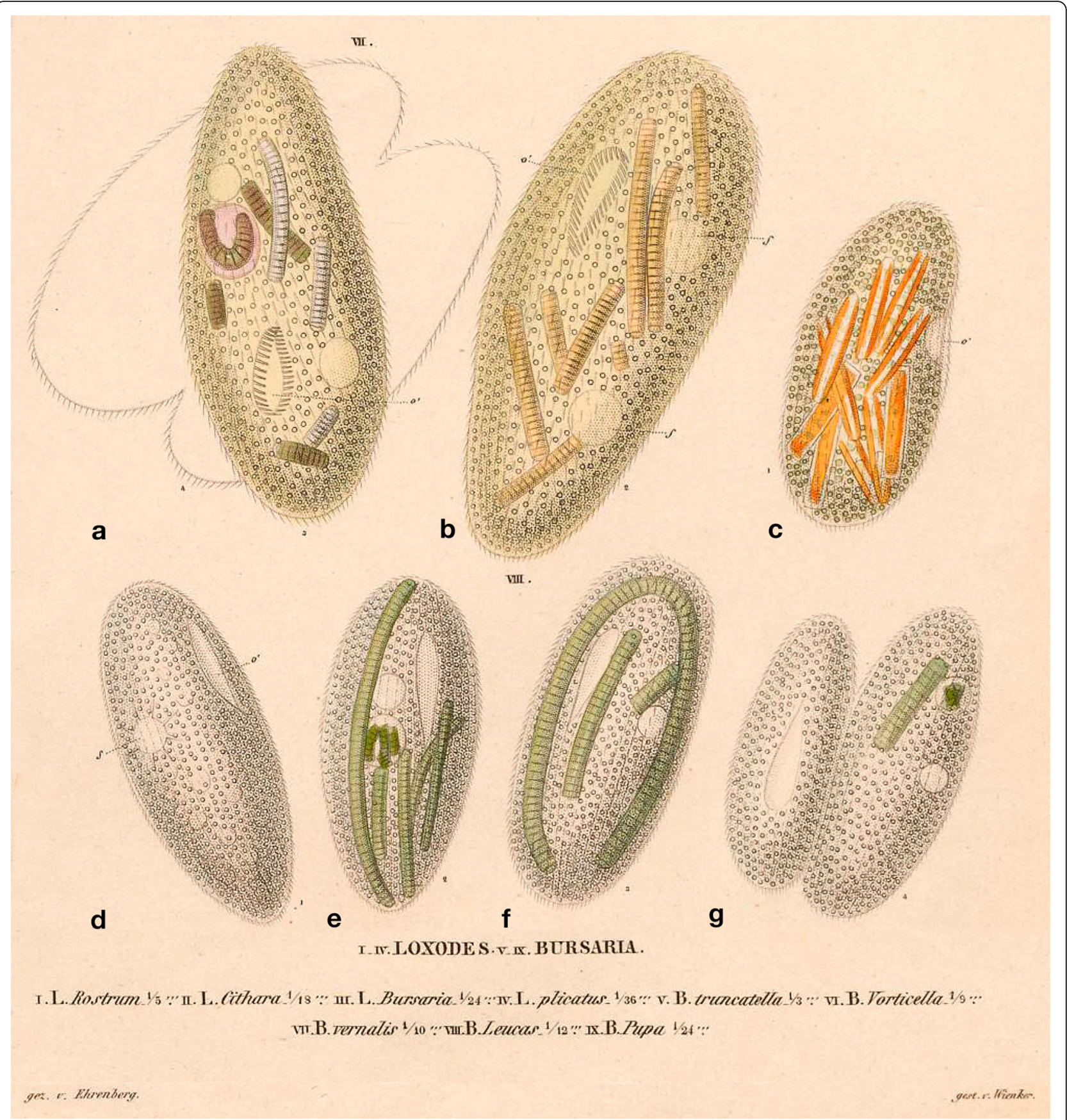

Fig. 1 Original drawing of Frontonia vernalis (a-c) and F. leucas (d-g) made by Ehrenberg in 1838: part of Plate 34, Figs VII, VIII (Ehrenberg, 1838 Atlas). In this study Ehrenberg simply reproduced the main part of drawing of F. vernalis made by himself in 1833 ([29]: p. 383, Plate III). a, b Two large green cells in which two vacuoles are depicted, but without collecting canals. Behind the first $F$. vernalis cell (a), there is the profile of a conjugating pair, which the Author interpreted as a dividing cell; $\mathbf{c}$ a much smaller green cell, in which only a single contractile vacuole is visible; $\mathbf{d}, \mathbf{e}, \mathbf{f}$ three white cells of $F$. leucas with one contractile vacuole each. In the left most cell (d) collecting canals of contractile vacuole are visible; $\mathbf{g}$ conjugating pair of $F$. leucas, which again was interpreted by the Author as a dividing cell. Small transparent drops spread over the cells of $F$. vernalis and F. leucas are, apparently, trichocysts. The image is not copyrighted due to the age of the work

ciliates with a single $\mathrm{CV}$ were repeatedly reported in the literature $[4,15,18,22,33,38-41]$.

In the present work, we propose the neotypification of F. vernalis, deeply analysing the available literature on
Frontonia species bearing intracytoplasmic green algae (from now on "green Frontonia spp." or "green frontoniids"), with a careful revision and re-interpretation of data presented by Ehrenberg. Along with F. vernalis, we 
found and described by means of a multimethod study $[16,36,37]$ a novel species of green frontoniid, F. paravernalis sp. nov., closely related to the $F$. vernalis group. Moreover, based on the $18 \mathrm{~S}$ rDNA sequences of the endosymbionts of $F$. vernalis and $F$. paravernalis, a reconstruction of the phylogenetic relationships within the Chlorella-clade is provided.

A critical discussion about the current status of the Frontonia taxonomy and phylogeny is presented as well. To better accomplish this goal we included in the analysis the $18 \mathrm{~S}$ rDNA sequences we produced in the last 15 years from other 14 frontoniids isolated in different parts of the world (Table 1), with a corresponding morphological diagnosis of each retrieved species. Among them, at least two resulted new species, and four of them were already known frontoniids (i.e., F. atra, F. fusca, F. minuta, and $F$. vesiculosa) for which the gene sequence was not yet published.

Moreover, in the present study, we tried to fix the Frontonia type species issue, providing the neotypification of $F$. leucas based on the diagnosis of an Italian population. Finally, a guideline for an accurate morphological description of Frontonia species is proposed at the end of the Discussion section.

\section{Results}

\section{Neotypification of Frontonia vernalis (Ehrenberg, 1833)} Ehrenberg, 1838

Class Oligohymenophorea de Puytorac et al., 1974

Order Peniculida Fauré-Frémiet in Corliss (1956)

Family Frontoniidae Kahl, 1926

Genus Frontonia Ehrenberg 1838

\section{Frontonia vernalis}

1833 Bursaria vernalis N. sp. Ehrenberg, Abh. K. Preuss. Akad. Wiss., P. 235. Pl. III

1838 Bursaria (Frontonia) vernalis Ehrenberg, Infusionsthierchen, P. 325. Pl. XXXIV, Fig. VII,

1841 Panophrys (Bursaria) vernalis Dujardin, Histoire

Naturelle Des Zoophytes., P. 493. Pl. 32, Fig. 7.

1889 Frontonia leucas Schewiakoff, Beitr. Kennt. Holo-

trich. Ciliat. P. 40. Fig. 58.

1896 Frontonia leucas synon. vernalis Schewiakoff,

Org.Sistem. Infus. Auctor. P. 312. Pl. V, Fig. 113.

1922 Frontonia leucas Penard, Etude infusoir. douce P. 139. Fig. 29.

1931 Frontonia vernalis Kahl, Tierwelt Deutsch. I. Wimp. Ciliata P. 317.

1943 Frontonia vernalis Kahl, Infusor. Handbuch. Prakt. repr. Acta Protistol. 43 (suppl.) P. 55.

1986 Frontonia vernalis Berninger et al., J. Protozool 33, P. 557. Fig. 6.

1986 Frontonia leucas Dragesco, Dragesco-Kerneis, Cilies libr. l'Afrique intertropic. P.318. Fig. 81b
2010 Frontonia vernalis Esteban et al., Protist 161, P. 629. Fig. 1e.

\section{Diagnosis}

Size in vivo $250 \times 125 \mu \mathrm{m}$ on average, size after staining $218.3 \times 99.5 \mu \mathrm{m}$ on average; cytostome/body length ratio: 1/7; 120-145 somatic kineties; macronucleus (Ma): $75.9 \times 40.7 \mu \mathrm{m}$ in size; micronucleus $(\mathrm{Mi}): 3-9$, compacttype, $5.3 \times 3.4 \mu \mathrm{m}$ in size; peniculi: $4+4+4$; vestibular kineties (VKs): 3; postoral kineties (PKs): 6-7; paroral membrane (PM): single-rowed; contractile vacuole $(\mathrm{CV})$ : single, with 8-13 canals; pore of contractile vacuole (PCV): single, on the dorsal side; pre-suture is continue on the dorsal side; pigment granules are absent; cysts not detected; during swimming ciliate rotation mainly to the right and, with less frequently, to the left direction. Several hundreds of Chlorella-like organisms $(4-6 \mu \mathrm{m}$ in diameter each) borne in ciliate cytoplasm. Freshwater.

\section{Neotype locality}

The sampling site of the neotype population of $F$. vernalis $(\mathrm{IPS} a \mathrm{l}+\mathrm{b})$ is the permanent freshwater shallow small pond located along the Ligurian sea coastline close to the mouth of Serchio River (Parco Naturale di Migliarino San Rossore Massaciuccoli, Migliarino, Pisa district,

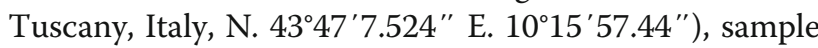
№ 7 (sampling date 1 February 2017; collector S. I. Fokin).

\section{Neotype material}

One neotype slide with silver nitrate stained neotype specimen (registration number: CAMUS_2020-1), indicated by a circle of ink on the coverslip, plus a paratype slide with permanent Feulgen stained specimens (registration number: CAMUS_2020-2) have been deposited in the collection of the "Museo di Storia Naturale e del Territorio dell'Università di Pisa” (Calci, Pisa, Italy).

\section{Voucher material}

The total genomic DNA of the species obtained from cells of the neotype population is available at the Department of Biology of the University of Pisa, ZoologyAnthropology Unit. The $18 \mathrm{~S}$ rDNA sequence of $F$. vernalis results (population IPSal+b) $1708 \mathrm{bp}$ long and is deposited in NCBI GenBank database under the accession number MT040840.

\section{Occurrence and ecology}

Probably, a population (FSPBb) of the same species has been detected also in the Russian site: the small permanent ditch, Old Peterhof, St. Petersburg district, Russia

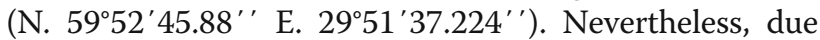
to the lack of molecular data on the latter population, 
Table 1 Sampling information and accession numbers of Frontonia species from the present study

\begin{tabular}{|c|c|c|c|c|c|c|c|}
\hline Species & Population & Sampling site & Country & Coordinates & Year & Habitat & Seq. ID \\
\hline $\begin{array}{l}\text { Frontonia vernalis- } \\
\text { Neotype }\end{array}$ & IPSal+b & Mouth of Serchio River, Pisa & Italy & $\begin{array}{l}\text { N. } 43^{\circ} 47^{\prime} 7.524^{\prime \prime} \text { E. } 10^{\circ} 15^{\prime} \\
57.44^{\prime \prime}\end{array}$ & 2017 & Freshwater & MT040840 \\
\hline Frontonia sp..$^{a}$ & $\mathrm{FSPBb}$ & Old Peterhof, St. Petersburg & Russia & $\begin{array}{l}\text { N. } 59^{\circ} 52^{\prime} 45.88^{\prime \prime} \text { E. } 29^{\circ} 51^{\prime} \\
37.224^{\prime \prime}\end{array}$ & 2016 & Freshwater & NO DATA \\
\hline Frontonia paravernalis & IPSal+sm & Mouth of Serchio River, Pisa & Italy & $\begin{array}{l}\text { N. } 43^{\circ} 47^{\prime} 7.524^{\prime \prime} \text { E. } 10^{\circ} 15^{\prime} \\
57.44^{\prime \prime}\end{array}$ & 2017 & Freshwater & MT040839 \\
\hline Frontonia paravernalis & FSPBsm & Old Peterhof, St. Petersburg & Russia & $\begin{array}{l}\text { N. } 59^{\circ} 52^{\prime} 45.88^{\prime \prime} \text { E. } 29^{\circ} 51^{\prime} \\
37.224^{\prime \prime}\end{array}$ & 2016 & Freshwater & МT040838 \\
\hline Frontonia sp. & IPSal- & Mouth of Serchio River, Pisa & Italy & $\begin{array}{l}\text { N. } 43^{\circ} 47^{\prime} 7.524^{\prime \prime} \text { E. } 10^{\circ} 15^{\prime} \\
57.44^{\prime \prime}\end{array}$ & 2017 & Freshwater & MT040841 \\
\hline Frontonia sp. & $\mathrm{VmFr}$ & Monte Urpino Park, Cagliari & Italy & $\begin{array}{l}\text { N. } 39^{\circ} 13^{\prime} 2.716^{\prime \prime} \text { E. } 9^{\circ} 8^{\prime} \\
1.345^{\prime \prime}\end{array}$ & 2017 & Freshwater & MT040842 \\
\hline Frontonia sp. & BJ4 & Balugoan Jetty, Chilka Lake, Odisha & India & $\begin{array}{l}\text { N. } 19^{\circ} 44^{\prime} 37.021^{\prime \prime} \text { E. } 85^{\circ} \\
12^{\prime} 44.398^{\prime \prime}\end{array}$ & 2014 & $\begin{array}{l}\text { Brackish } \\
\text { water }\end{array}$ & МТ040843 \\
\hline Frontoni atra & F4 & Mouth of Serchio River, Pisa & Italy & $\begin{array}{l}\text { N. } 43^{\circ} 47^{\prime} 7.524^{\prime \prime} \text { E. } 10^{\circ} 15^{\prime} \\
57.44^{\prime \prime}\end{array}$ & 2005 & Freshwater & МT040844 \\
\hline Frontonia fusca & F3 & Mouth of Serchio River, Pisa & Italy & $\begin{array}{l}\text { N. } 43^{\circ} 47^{\prime} 7.524^{\prime \prime} \text { E. } 10^{\circ} 15^{\prime} \\
57.44^{\prime \prime}\end{array}$ & 2005 & $\begin{array}{l}\text { Brackish } \\
\text { water }\end{array}$ & MT040845 \\
\hline Frontonia leucas & IPBG & $\begin{array}{l}\text { Pond in Botanical garden of University } \\
\text { of Pisa, Pisa }\end{array}$ & Italy & $\begin{array}{l}\text { N. } 43^{\circ} 43^{\prime} 10.97^{\prime \prime} \text { E. } 10^{\circ} 23^{\prime} \\
45.387^{\prime \prime}\end{array}$ & 2005 & Freshwater & AM072622 \\
\hline Frontonia leucas & KNP3 & Kolleru lake, Andhra Pradesh & India & $\begin{array}{l}\text { N. } 16^{\circ} 43^{\prime} 10.2^{\prime \prime} \text { E. } 81^{\circ} 19^{\prime} \\
35.2^{\prime \prime}\end{array}$ & 2016 & Freshwater & KY855558 \\
\hline Frontonia minuta & F2 & Mouth of Serchio River, Pisa & Italy & $\begin{array}{l}\text { N. } 43^{\circ} 47^{\prime} 7.524^{\prime \prime} \text { E. } 10^{\circ} 15^{\prime} \\
57.44^{\prime \prime}\end{array}$ & 2005 & Freshwater & МT040846 \\
\hline Frontonia paramagna & KTC4 & Kolleru lake, Andhra Pradesh & India & $\begin{array}{l}\text { N. } 16^{\circ} 43^{\prime} 18.1^{\prime \prime} \text { E. } 81^{\circ} 19^{\prime} \\
37.3^{\prime \prime}\end{array}$ & 2014 & Freshwater & KY855559 \\
\hline Frontonia paramagna & KKR19 & Kolleru lake, Andhra Pradesh & India & $\begin{array}{l}\text { N. } 16^{\circ} 43^{\prime} 10.2^{\prime \prime} \text { E. } 81^{\circ} 19^{\prime} \\
35.2^{\prime \prime}\end{array}$ & 2014 & Freshwater & KY855554 \\
\hline Frontonia paramagna & $M L$ & $\begin{array}{l}\text { Mudasarlova Garden, Visakhapatnam, } \\
\text { Andhra Predesh }\end{array}$ & India & $\begin{array}{l}\text { N. } 17^{\circ} 45^{\prime} 43.175^{\prime \prime} \text { E. } 83^{\circ} \\
17^{\prime} 47.302^{\prime \prime}\end{array}$ & 2015 & Freshwater & LT628495 \\
\hline Frontonia paramagna & $\mathrm{BDM} 3$ & Boddam pond, Andhra Pradesh & India & $\begin{array}{l}\text { N. } 18^{\circ} 3^{\prime} 59.425^{\prime \prime} \text { E. } 83^{\circ} 8^{\prime} \\
34.346^{\prime \prime}\end{array}$ & 2014 & Freshwater & MT040847 \\
\hline Frontonia paramagna & KT1 & Kottavuro pond, Andhra Pradesh & India & $\begin{array}{l}\text { N. } 18^{\circ} 5^{\prime} 34.764^{\prime \prime} \text { E. } 83^{\circ} 8^{\prime} \\
10.557^{\prime \prime}\end{array}$ & 2014 & Freshwater & MT040848 \\
\hline Frontonia paramagna & GVMC17 & $\begin{array}{l}\text { Mudasarlova Garden, Visakhapatnam, } \\
\text { Andhra Predesh }\end{array}$ & India & $\begin{array}{l}\text { N. } 17^{\circ} 45^{\prime} 43.175^{\prime \prime} \text { E. } 83^{\circ} \\
17^{\prime} 47.302^{\prime \prime}\end{array}$ & 2014 & Freshwater & МT040849 \\
\hline Frontonia vesiculosa & KP2 & $\begin{array}{l}\text { Gosthani River near Kasipatnam, Andhra } \\
\text { Pradesh }\end{array}$ & India & $\begin{array}{l}\text { N. } 18^{\circ} 13^{\prime} 1.747^{\prime \prime} \text { E. } 83^{\circ} 6^{\prime} \\
41.954^{\prime \prime}\end{array}$ & 2014 & Freshwater & МТ040850 \\
\hline
\end{tabular}

Seq. ID: accession number of 18S rDNA sequence deposited on GenBank

${ }^{a}$ Morphologically close to Frontonia vernalis (IPSal+b)

the species attribution for Russian Frontonia FSPBb remains uncertain.

\section{Morphological description of neotype population of Frontonia vernalis}

Italian population, IPSal+b (Figs. 2 and 3). Cell shape ovoid with a broadly rounded anterior end and a narrower, rounded posterior end in vivo (Fig. 2a, b). Cells dorso-ventrally flattened. Size about $220-300 \times 120-$ $140 \mu \mathrm{m}$ in vivo $(250 \times 125 \mu \mathrm{m}$ on average). Silver stained ciliates shorter (on average): $218.3 \times 99.5 \mu \mathrm{m}$ (Table 2). Length:width ratio close to 2:1. Somatic cilia about $10 \mu \mathrm{m}$ long; caudal cilia sometimes slightly longer.
Meridional ciliary rows, around $120-145$, visible in silver stained cells: 60-72 ventral, 60-73 dorsal (Fig. 3e, f; Table 2). Some ventral ciliary rows (especially in the posterior part of the left side) terminating before the end of the body, approaching the postoral suture. Postoral suture conspicuous, running almost to the posterior pole of the body, consisting of some empty spaces from the right side and twisted argentophilic fold in the pellicle from the left side of the structure (Fig. 3a, c, e). Cytoproct, blending into this fold, difficult to detect. On the dorsal side postoral suture not observed (Fig. 3f).

Preoral suture presenting an empty space going on, from upper side of buccal aperture to the right-anterior 


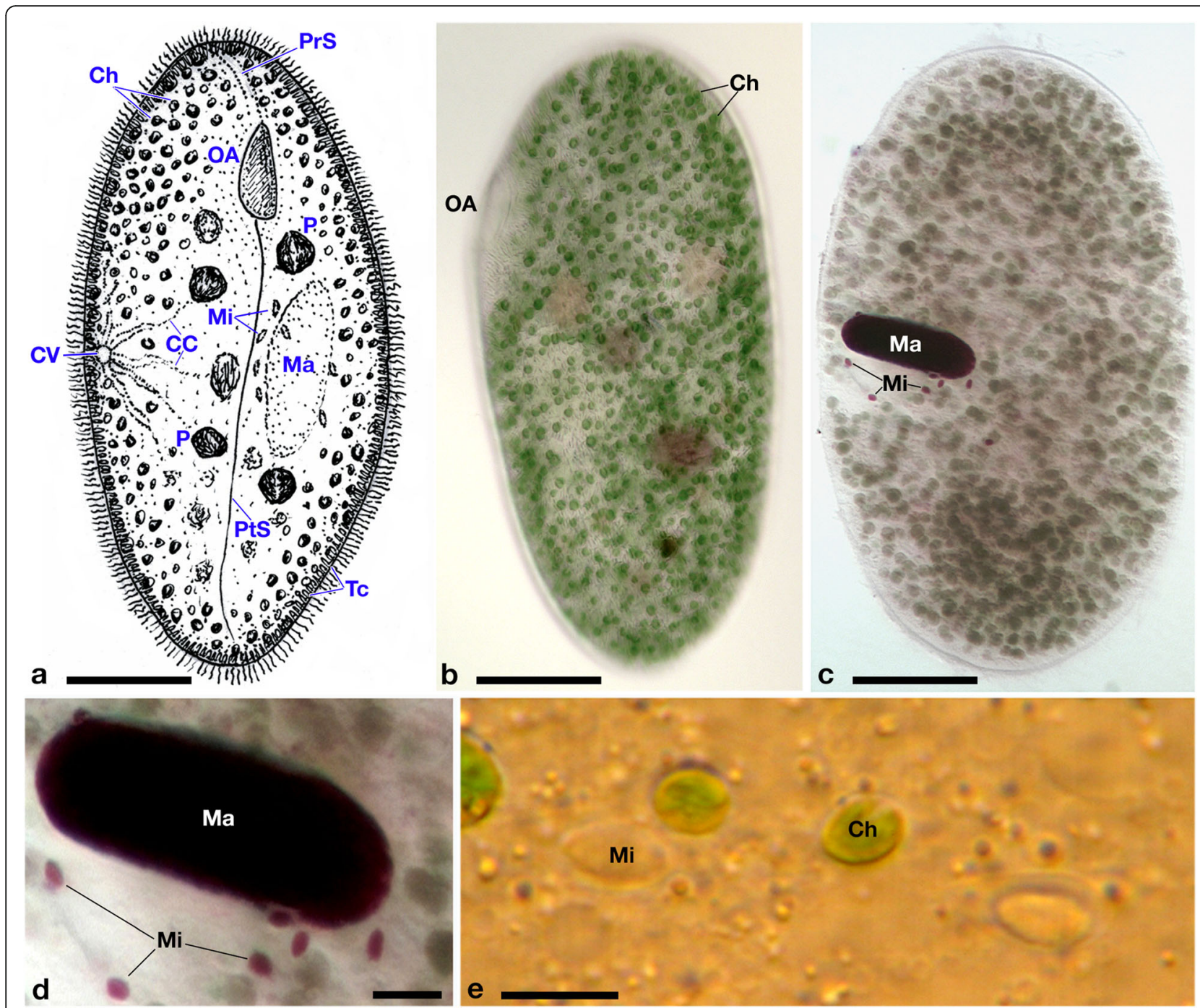

Fig. 2 Morphology of Frontonia vernalis population IPSal + b (Neotype). a Schematic drawing of the ventral side; b live cell bearing Chlorella-like (Ch) endosymbiotic algae; $\mathbf{c}$ nuclear apparatus after Feulgen stainining, showing the macronucleus (Ma) and several micronuclei (Mi); $\mathbf{d}$ closer view of Ma and "compact type" Mi after Feulgen staining; e detail of Mi morphology and location in live cell, plus detail of Chlorella-like endosymbiont (Ch). CC - collecting canals; CV - contractile vacuole; OA - oral aperture; P - phagosomes; PrS - preoral suture, PtS - postoral suture; Tc - trichocysts. Bars stand for $50 \mu \mathrm{m}(\mathbf{a}-\mathbf{c}), 10 \mu \mathrm{m}(\mathbf{d}), 5 \mu \mathrm{m}(\mathbf{e})$

part of dorsal side (Figs. 2a and 3f). In the dorsal side, several kinetosomal rows (8-10), beneath the preoral suture end, travelling parallelly to each other, with an angle of $45^{\circ}$ respect with the longitudinal axis of cell (Fig. 3f). On the left, in the middle of dorsal side, 3-4 kineties tightly close to each other, forming a visible longitudinal strip in the kinetome (Fig. 3f).

Basal bodies on the ventral side (around the oral region) consisting of dikinetids, in the dorsal side consisting of monokinetids (Fig. 3a, c). Kinetosomes of oral region forming triplets after impregnation: dikinetids + parasomal sacs (Fig. 3a, c).

Buccal apparatus, $1 / 7$ of body length, about $32 \mu \mathrm{m}$, located on the ventral side, about $18 \%$ back from anterior body end (Figs. 2a and 3a, c, e). Formed by three symmetrical, almost parallel and slightly curved peniculi on the buccal left side, composed of four rows of basal bodies each (Fig. 3a, c; Table 2). Peniculi showing (I+II+ III) $4+4+4$ rows of cilia, with peniculus III presenting 1-2 rows of cilia in its posterior end (Fig. 3a, c); from the right side, the buccal cavity presenting a single-rowed PM, closely associated with the first VK (Fig. 3a, c). Three VKs, gradually elongating posteriorly from left to right (Fig. 3a, c). PKs, 6-7, gradually shortening from the left posterior angle of buccal cavity to postoral suture (Fig. 3a, c, e). Single CV with almost straight 8-13 collecting canals, not always well-visible, with a single PCV opening on 


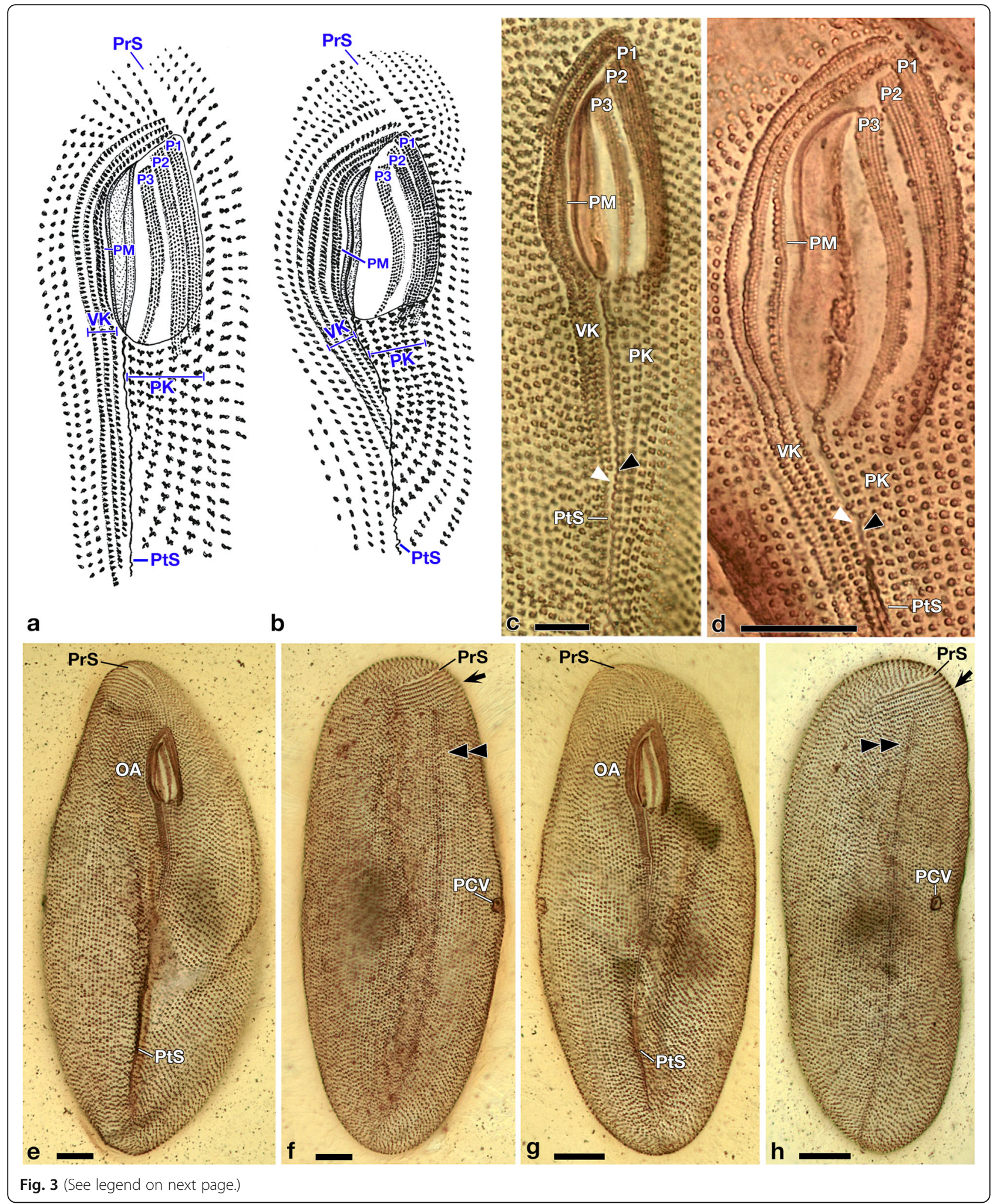


(See figure on previous page.)

Fig. 3 Oral and somatic ciliature of Frontonia vernalis (Neotype) (a, c, e, $\mathbf{f})$ and Frontonia paravernalis sp. nov. (b, $\mathbf{d}, \mathbf{g}, \mathbf{h})$ after silver impregnation. a Schematic drawing of oral apparatus of F. vernalis; $\mathbf{b}$ schematic drawing of oral apparatus of $F$. paravernalis; c closer view of $F$. vernalis oral ciliature and of the postoral suture (PtS), formed by a cortex folding (black arrowhead) and by an empty line, free of cilia (white arrowhead); $\mathbf{d}$ closer view of F. paravernalis oral ciliature and of the PtS; $\mathbf{e}, \mathbf{f}$ ventral and dorsal somatic ciliature of $F$. vernalis; $\mathbf{g}, \mathbf{h}$ ventral and dorsal somatic ciliature of F. paravernalis. OA - oral aperture; P1, P2, P3 - first, second, third peniculus; PCV - pore of contractile vacuole; PK - postoral kineties; PM - paroral membrane; PrS - preoral suture; PtS - postoral suture; VK - vestibular kineties; Arrow - dorsal set of kineties parallel to the preoral suture; Black Arrowhead - cortex folding, similar to a comb, forming part of the PtS; Double Arrowhead - longitudinal dorsal stripe of adjacent kineties; White Arrowhead - cortex line, free of cilia, forming part of the PtS. Bars stand for $20 \mu \mathrm{m}(\mathbf{e}-\mathbf{h}), 10 \mu \mathrm{m}(\mathbf{c}, \mathbf{d})$

the right part of the dorsal side, in the equator of the cell (Fig. 2a). PCV usually well visible, rounded, occupying the space of 3-4 ciliary rows (Fig. 3f).

Numerous resting spindle-shaped extrusomes (trichocysts), about $8 \mu \mathrm{m}$ long and $1.5 \mu \mathrm{m}$ wide, with a conical arrowhead-like tip, and a rounded crosssection; similar to those of Paramecium or majority of other frontoniids (Fig. 2a). Extruded organelles about 10-11 times the length of those in resting state, resembling transparent spines. Ma in mid-body position; always ellipsoidal, $62.0-85.5 \times 35.0-45.3 \mu \mathrm{m}$ in size, after Feulgen staining (Fig. 2c, d; Table 2). Several compact-type Mi (3-9; in average 5), $5.3 \times$ $3.4 \mu \mathrm{m}$ in size after Feulgen staining, usually located close to the Ma (Fig. 5c, d; Table 2).

Despite the morphology of the Russian population (FSPBb) appears consistent with that of the Italian population (IPSal+b), without supporting molecular data we must be cautious, avoiding referring to it as $F$. vernalis. mainly containing bacteria, diatoms, and dinoflagellates were usually present in the cytoplasm of ciliates, freshly isolated from native population (Fig. $2 b, e$ ).

\section{Biology}

In the native environment, cells of $F$. vernalis appeared mainly concentrated on the surface or slightly beneath of bottom sediments, but they also occurred in pelagic part of the water column. The ciliate preferably swam rotating to the right, but sometimes it could switch to the left spiral as well, with respect to the longitudinal body axis. Resting cysts not observed. Apparently, this frontoniid ciliate species could also eat rotifers and some other ciliates (preferably Euplotes). We did not succeed to keep the ciliate in culture using the dinoflagellate Peridinium sp. as food as indicated by UK colleagues, who cultivated the species they referred to as " $F$. vernalis" in the laboratory [33].

\section{Endosymbionts and other inclusions}

Endosymbiotic Chlorella-like algae were present in the cytoplasm of $F$. vernalis (see Results and Discussion sections). No additional symbionts other than cytoplasmic green algae were observed either in the cytoplasm or in the nuclear apparatus of the ciliates. Some inclusions of different size and unknown nature, and food vacuoles

\section{Molecular identification}

The $18 \mathrm{~S}$ rDNA sequence of $F$. vernalis IPSal+b (MT040840) showed the highest identity with sequences of F. shii (MF279208) and "F. vernalis" (U97110): 99.3\% (ten mismatches) and 99.2\% (one gap, 23 mismatches), respectively (Table 3 ).

Table 2 Morphometric data on Frontonia vernalis, Serchio population (IPSal+b) - Neotype, Italy

\begin{tabular}{|c|c|c|c|c|c|c|}
\hline Characters & $\bar{X}$ & SD & Min & Max & CV & $\mathrm{n}$ \\
\hline Body, length $^{a}$ & 218.3 & 16.4 & 183.0 & 247.0 & 7.51 & 20 \\
\hline Body, width ${ }^{a}$ & 99.5 & 14.3 & 73.3 & 120.0 & 14.4 & 20 \\
\hline Somatic ciliary rows, ventral side, number & 66.7 & 3.9 & 60 & 72 & 5.8 & 12 \\
\hline Somatic ciliary rows, dorsal side, number & 63.0 & 17.3 & 60 & 73 & 27.5 & 12 \\
\hline Excretory pores, number & 1 & 0 & 1 & 1 & 0 & 15 \\
\hline Macronucleus, length ${ }^{\mathrm{b}}$ & 75.9 & 8.0 & 62.0 & 85.5 & 10.5 & 18 \\
\hline Macronucleus, width ${ }^{b}$ & 40.7 & 3.9 & 35.0 & 45.3 & 9.6 & 18 \\
\hline Micronucleus, number & 5.1 & 1.9 & 3 & 9 & 36.6 & 16 \\
\hline Micronucleus size, length ${ }^{b}$ & 5.3 & 0.7 & 4.0 & 7.5 & 14.7 & 18 \\
\hline Micronucleus size, width ${ }^{b}$ & 3.4 & 0.6 & 2.5 & 4.5 & 16.9 & 18 \\
\hline
\end{tabular}

$\bar{X}$ Arithmetic mean, SD Standard deviation, Min Minimum, Max Maximum, CV Coefficient of variation in percentage, $n$ Number of investigated cells

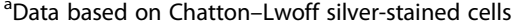

${ }^{\mathrm{b}}$ Macro- and micronuclei were measured from Feulgen-stained ciliates. Measurements in $\mu \mathrm{m}$ 
Table 3 Identity values among green frontoniids and selected Frontonia 18S rDNA sequences

\begin{tabular}{|c|c|c|c|c|c|c|c|c|c|c|c|c|c|c|c|c|c|c|c|}
\hline & & a. & b. & c. & d. & e. & f. & g. & h. & i. & j. & k. & I. & m. & n. & o. & p. & q. & r. \\
\hline a. & Frontonia paramagna ${ }^{a}$ & 100 & & & & & & & & & & & & & & & & & \\
\hline b. & Frontonia paramagna MF279207 & 100 & 100 & & & & & & & & & & & & & & & & \\
\hline c. & Frontonia paramagna JQ868786 & 99.9 & 100 & 100 & & & & & & & & & & & & & & & \\
\hline d. & Frontonia vesiculosa (KP2) & 99.4 & 99.4 & 99.4 & 100 & & & & & & & & & & & & & & \\
\hline e. & Frontonia sp. (VmFr) & 98.5 & 98.6 & 98.5 & 98.6 & 100 & & & & & & & & & & & & & \\
\hline f. & Frontonia sp. (IPSal-) & 98.5 & 98.6 & 98.5 & 98.6 & 100 & 100 & & & & & & & & & & & & \\
\hline g. & Frontonia sp. AF255359 & 98.7 & 98.6 & 98.6 & 98.6 & 99.8 & 99.8 & 100 & & & & & & & & & & & \\
\hline h. & $\begin{array}{l}\text { Frontonia paravernalis (IPSal + } \\
\mathrm{sm})\end{array}$ & 98.4 & 98.4 & 98.3 & 98 & 98 & 98 & 98.2 & 100 & & & & & & & & & & \\
\hline i. & $\begin{array}{l}\text { Frontonia paravernalis } \\
\text { (FSPBsm) }\end{array}$ & 98.4 & 98.4 & 98.3 & 98 & 98 & 98 & 98.2 & 100 & 100 & & & & & & & & & \\
\hline j. & "Frontonia vernalis" U97110 & 98.5 & 98.6 & 98.5 & 98.2 & 98.2 & 98.2 & 98.2 & 99 & 99 & 100 & & & & & & & & \\
\hline k. & Frontonia shii MF279208 & 98.6 & 98.6 & 98.6 & 98.2 & 98.2 & 98.2 & 98.3 & 99.1 & 99.1 & 99.2 & 100 & & & & & & & \\
\hline I. & $\begin{array}{l}\text { Frontonia vernalis (IPSal + b) - } \\
\text { Neotype }\end{array}$ & 98.8 & 98.8 & 98.8 & 98.6 & 98.4 & 98.4 & 98.5 & 99 & 99 & 99.2 & 99.3 & 100 & & & & & & \\
\hline $\mathrm{m}$. & Uncultured ciliate EU910593 & 97.5 & 97.5 & 97.5 & 97.3 & 97.5 & 97.5 & 97.6 & 97.7 & 97.7 & 97.5 & 97.6 & 97.7 & 100 & & & & & \\
\hline n. & "Frontonia angusta" (?) MG456580 & 96.9 & 96.9 & 96.9 & 96.9 & 96.5 & 96.5 & 96.6 & 96.9 & 96.9 & 96.6 & 96.7 & 96.9 & 97.7 & 100 & & & & \\
\hline o. & Frontonia leucas (IPBG) AM072622 & 97.1 & 97.1 & 97 & 97.1 & 96.6 & 96.6 & 96.8 & 97.1 & 97.1 & 96.8 & 96.8 & 97.1 & 97.8 & 99.9 & 100 & & & \\
\hline p. & Frontonia leucas (KNP3) & 97.1 & 97.1 & 97 & 97.1 & 96.6 & 96.6 & 96.8 & 97.1 & 97.1 & 96.7 & 96.8 & 97.1 & 98.1 & 99.4 & 99.5 & 100 & & \\
\hline q. & Uncultured ciliate EU910594 & 97.1 & 97.1 & 97 & 97.1 & 96.6 & 96.6 & 96.8 & 97.1 & 97.1 & 96.7 & 96.8 & 97.2 & 97.7 & 99.2 & 99.3 & 99.5 & 100 & \\
\hline r. & Frontonia sp. KJ475307 & 96.7 & 96.7 & 96.6 & 96.8 & 96.6 & 96.6 & 96.8 & 96.8 & 96.8 & 96.5 & 96.7 & 96.9 & 97.4 & 97.8 & 97.8 & 98 & 97.9 & 100 \\
\hline
\end{tabular}

Identity values obtained via distance matrix calculation by ARB program; sequences obtained in present work are shown in bold

${ }^{a}$ Frontonia paramagna ML, KTC4, KKR19, BDM3, KT1, GVMC17 populations

Description of Frontonia paravernalis sp. nov.

Class Oligohymenophorea de Puytorac et al., 1974

Order Peniculida Fauré-Frémiet in Corliss (1956)

Family Frontoniidae Kahl, 1926

Genus Frontonia Ehrenberg, 1838

Frontonia paravernalis sp. nov.

\section{Diagnosis}

Size in vivo $178 \times 95 \mu \mathrm{m}$ on average, size after staining $159.0 \times 90.2 \mu \mathrm{m}$ on average; length:width ratio $1.8: 1$; cytostome/body length ratio: $1 / 6$; $98-116$ somatic kineties; Ma: $48.5 \times 23.2 \mu \mathrm{m}$ in size; Mi:1-3 (usually 2), compact-type, $3.4 \times 2.6 \mu \mathrm{m}$ in size; peniculi: $4+4+4$; VKs: 3-4 (mainly 4); PKs: 5-7; PM: single-rowed; CV: single, with 8-11 canals; PCV: single, on the dorsal side (around $4.5 \mu \mathrm{m}$ in diameter); pre-suture continuing on dorsal side; pigment granules absent; no cysts found; during swimming, cell rotation mainly to the right, and less frequently to the left. Several hundreds of Chlorellalike organisms (4-6 $\mu \mathrm{m}$ in diameter) borne in cell cytoplasm. Freshwater.

\section{Type locality}

The sampling site of the type population of $F$. paravernalis $(\mathrm{IPSal}+\mathrm{sm})$ is the permanent freshwater shallow small pond located along the Ligurian sea coastline close to the mouth of Serchio River (Parco Naturale di Migliarino San Rossore Massaciuccoli, Migliarino, Pisa district, Tuscany, Italy, N. $43^{\circ} 47^{\prime} 7.524^{\prime \prime}$ E. $10^{\circ} 15^{\prime}$ 57.44"), sample № 7 (sampling date 1 February 2017; collector Fokin).

\section{Type material}

One holotype slide with silver nitrate stained holotype specimen (registration number: CAMUS_2020-3), indicated by a circle of ink on the coverslip, plus a paratype slide with permanent Feulgen stained specimens (registration number: CAMUS_2020-4) have been deposited in the collection of the "Museo di Storia Naturale e del Territorio dell'Università di Pisa” (Calci, Pisa, Italy).

\section{Etymology}

"Paravernalis", para, "beside; next to, near" from Ancient Greek pará ( $\pi \alpha \rho \alpha$ ); vernalis, from the specific epithet of $F$. vernalis, the first green Frontonia ever described which the novel species has many traits in common with.

\section{Voucher material}

The total genomic DNA of the species obtained from cells of the type population is available at the 
Department of Biology of the University of Pisa, Zoology-Anthropology Unit. The $18 \mathrm{~S}$ rDNA sequences of $F$. paravernalis resulted $1707 \mathrm{bp}$ long and were deposited in NCBI GenBank database under the accession numbers MT040839 (population IPSal+sm), and MT040838 (population FSPBsm).

\section{Occurrence and ecology}

The same species has been detected in Russia, in a small permanent ditch in Old Peterhof (St. Petersburg district, Russia, N. $59^{\circ} 52^{\prime} 45.88^{\prime \prime}$ E. $29^{\circ} 51^{\prime} 37.224^{\prime \prime}$ ), sample № 3 (sampling date 16 August 2016; collector Fokin).

\section{Morphological description of type population}

Italian population, IPSal+sm (Figs. 3, 4 and 5). Cell shape ovoid with rounded anterior and posterior ends in vivo (Fig. 4a, b). Cells slightly dorsoventrally flattened. Size about $140-190 \times 80-100 \mu \mathrm{m}$ in vivo (average $178 \times 95 \mu \mathrm{m}$ ). Silver stained ciliates are shorter: $159.0 \times 90.2 \mu \mathrm{m}$ on average (Table 4). Length:width ratio close to $1.8: 1$. Somatic cilia about $10 \mu \mathrm{m}$ long; caudal cilia sometimes slightly longer. Meridional ciliary rows 98-116, visible in silver stained cells: $48-58$ ventral, $50-58$ dorsal (Fig. 3g, h; Table 4). Some of the ventral ciliary rows (especially in the posterior part of the left side) terminating before the end of body, approaching the postoral suture. Suture very conspicuous, running almost to the posterior pole of the body, consisting of some little empty space from the right side and twisted argentophilic fold in the pellicle from the left side of the structure. Cytoproct, blending into this fold, difficult to detect. On the dorsal side, postoral suture not observed (Fig. 3h). Preoral suture consisting of as an empty space going on from the upper side of buccal aperture to the right-anterior part of the dorsal side (Figs. 3b, g and 4a). In the dorsal side several kinetosomal rows (6-8), beneath the preoral suture end, travelling parallelly to each other, with an angle of $45^{\circ}$ with respect to the longitudinal axis of cell (Fig. $3 \mathrm{~h})$. On the left, in the middle of dorsal side, 2-3 kineties tightly close to each other, forming a visible longitudinal strip in the kinetome (Fig. 3h). Basal bodies on the ventral side (around the oral region) consisting of dikinetids, in the dorsal consisting of monokinetids (Fig. 3b, d). Kinetosome units of oral region forming triplets after silver staining: dikinetids + parasomal sacs (Fig. 3b, d).

Buccal apparatus, $1 / 6$ of body length, about $28 \mu \mathrm{m}$, located on the ventral side, about $12 \%$ back from anterior body end (Figs. $3 g$ and 4a). Formed by three symmetrical, almost parallel and slightly curved peniculi on the buccal left side, composed of four rows of basal bodies each (Fig. 3b, d; Table 4). Peniculi showing (I+ II + III)
$4+4+4$ rows of cilia, with peniculus III presenting $2-3$ rows of cilia in its posterior end (Fig. 3b, d; Table 4); from the right side, buccal cavity presenting a singlerowed PM closely associated with the first vestibular kinety (Fig. 3b, d). VKs, 3-4 (mainly four), gradually elongating posteriorly from left to right (Fig. 3b, d, g). PKs, 57 , gradually elongated from postoral suture to the left posterior angle of buccal cavity (Fig. 3b, d, g). Single CV with almost straight $8-11$ collecting canals, with a single PCV opening on the right part of the dorsal side, in the equator of the cell (Fig. 4a, b, g; Table 4). PCV relatively large and rounded (around $4.5 \mu \mathrm{m}$ in diameter), occupying the space of 3-4 ciliary rows (Figs. $3 \mathrm{~h}$ and $4 \mathrm{~h}$ ).

Numerous resting spindle-shaped extrusomes (trichocysts), about $8 \mu \mathrm{m}$ long and $1.4 \mu \mathrm{m}$ wide, with conical, arrowhead-like tip, and a rounded cross section, similar to those of Paramecium or to those already described in Frontonia [42] (Fig. 4a, f). Extruded organelles measuring about ten times the length of those in resting state, resembling transparent spines. Mid body-located, slightly ellipsoidal Ma, 35.0-60.0 $\times 17.3-29.2 \mu \mathrm{m}$ in size after Feulgen staining (Fig. 4a, c-d; Table 4). One to three compact-type Mi (usually two), $3.4 \times 2.6 \mu \mathrm{m}$ in size after Feulgen staining, usually located close to the Ma (Figs. 4a, c-d and 5a; Table 4).

\section{Diagnosis of Russian population (FSPBsm)}

Size in vivo $190 \times 105 \mu \mathrm{m}$ on average; size after stainig $171.7 \times 100.4 \mu \mathrm{m}$ on average; length:width ratio $1.7: 1$; cytostome/body length ratio: $1 / 6 ; 77-113$ somatic kineties. Ma: $52.3 \times 28.4 \mu \mathrm{m}$ in size; Mi: $1-3$ (usually 2 ), compact-type, $3.9 \times 2.5 \mu \mathrm{m}$ in size. Peniculi: $4+4+4$; VKs: 3-4; PKs: 5-7. CV: single, with 8-11canals; PCV: one in the dorsal side (around $4.5 \mu \mathrm{m}$ in diameter); presuture continuing on dorsal side; pigment granules absent; no cysts found; during swimming, cell rotation mainly to the right, and less frequently to the left. Several hundreds of Chlorella-like organisms $(4-6 \mu \mathrm{m}$ in diameter) borne in cell cytoplasm. Freshwater (Suppl. Fig. 1; Table 4).

\section{Endosymbionts and other inclusions}

Endosymbiotic Chlorella-like organisms $(4-6 \mu \mathrm{m}$ in diameter) were detected in the cytoplasm of Italian and Russian frontoniids (Fig. 4a, b, i). Number of the endosymbiontic algae (about several hundred) varied from cell to cell; symbionts are mainly located below the cortical layer, but they could be detected in endoplasm as well (Figs. 4a, b, i and 5b). A certain divergence among the 18S rDNA sequences of Chlorella-like organisms from Italian and Russian frontoniids, suggests that different species of algae colonize $F$. paravernalis cells, depending on the sampling site (see further Results and Discussion sections). 


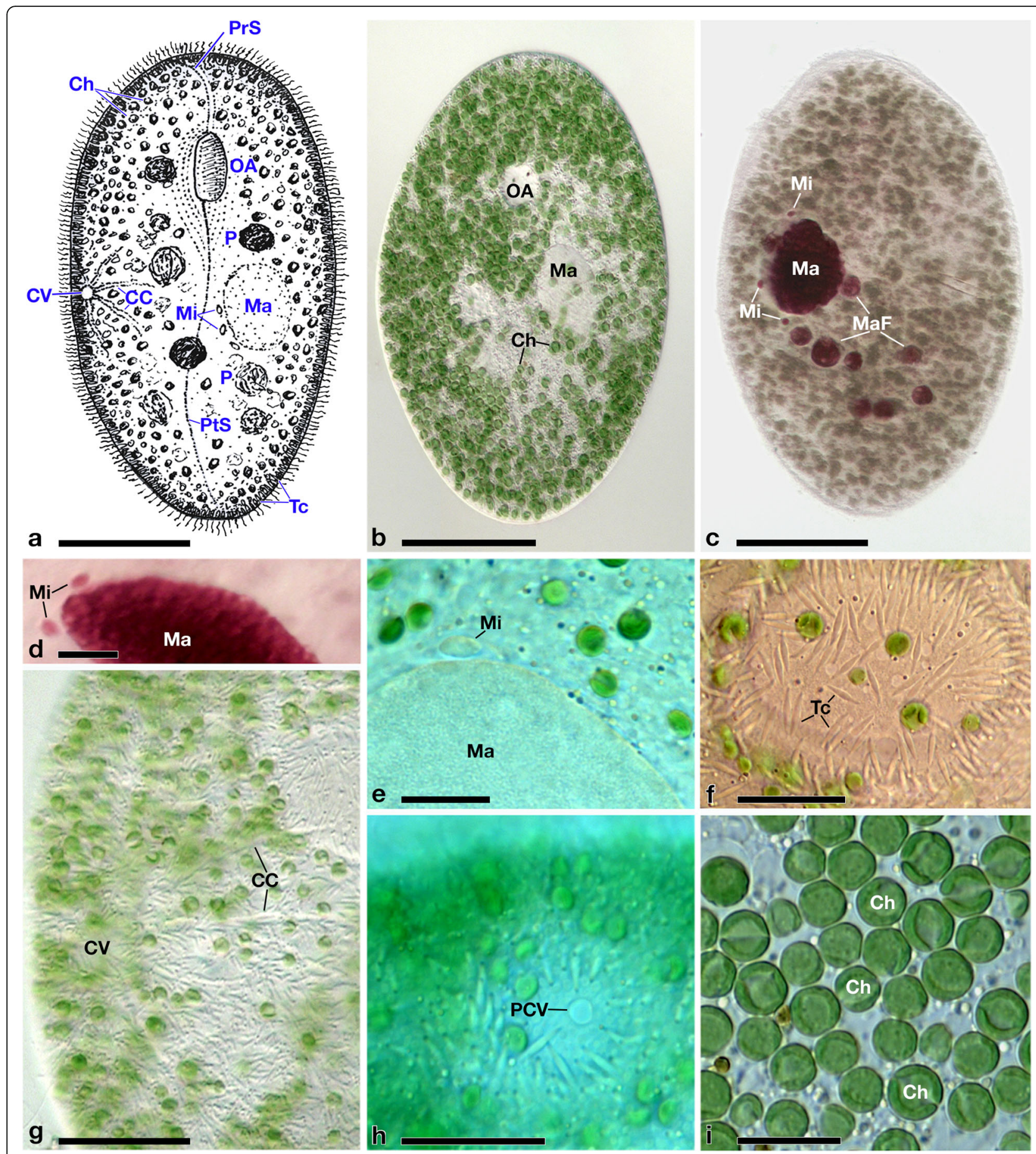

Fig. 4 Morphology of Frontonia paravernalis sp. nov (Italian population - IPSal +sm). a Schematic drawing of the ventral side; $\mathbf{b}$ live cell bearing Chlorella-like (Ch) endosymbiotic algae; c nuclear apparatus after Feulgen stainining, showing the macronucleus (Ma), several micronuclei (Mi) and the old macronuclear fragments (MaF); d closer view of Ma and "compact type" Mi after Feulgen staining; e detail of Mi morphology and location in living condition; $\mathbf{f}$ detail of trichocysts (Tc) in living cell; $\mathbf{g}$ closer view of contractile vacuoles (CV) and collecting canals (CC); $\mathbf{h}$ detail of the single pore of contractile vacuole (PCV) in living condition; i detail of Chlorella-like endosymbionts (Ch) after F. paravernalis cell disruption. CC collecting canals; Ch - Chlorella-like endosymbiont; CV - contractile vacuole; Ma - macronucleus; MaF - macronuclear fragment; Mi micronucleus; OA - oral aperture; P - phagosomes; PCV - pore of contractile vacuole; PrS - preoral suture, PtS - postoral suture; Tc - trichocysts. Bars stand for $50 \mu \mathrm{m}(\mathbf{a}-\mathbf{c}), 20 \mu \mathrm{m}(\mathbf{f}-\mathbf{h}), 10 \mu \mathrm{m}(\mathbf{d}, \mathbf{i}), 5 \mu \mathrm{m}(\mathbf{e})$ 


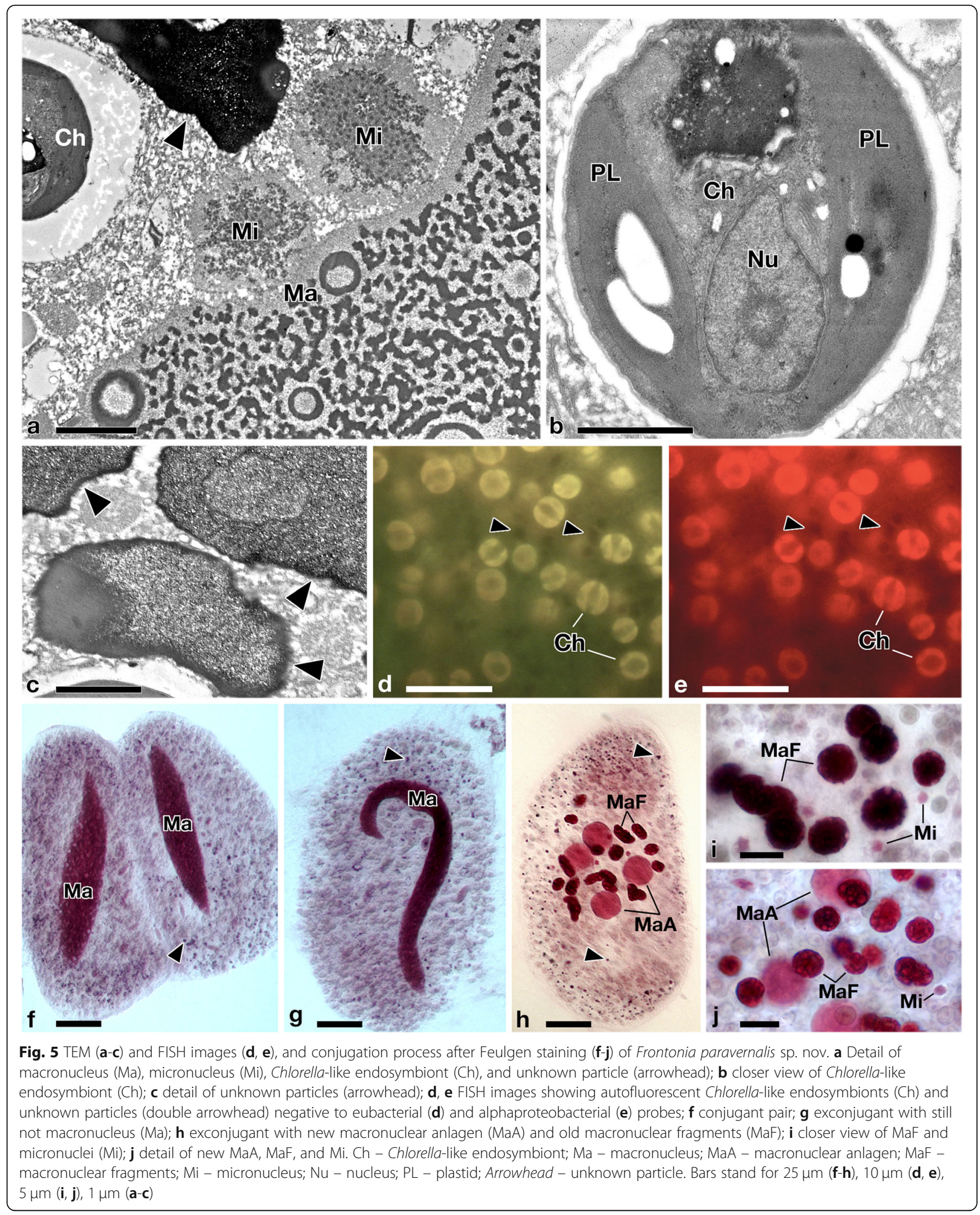


Table 4 Morphometric data on Frontonia paravernalis sp. nov.

\begin{tabular}{|c|c|c|c|c|c|c|}
\hline Characters & $\bar{x}$ & SD & Min & Max & CV & n \\
\hline \multirow[t]{2}{*}{ Body, length $^{a}$} & 159.0 & 21.6 & 142.0 & 170.0 & 13.6 & 33 \\
\hline & 171.7 & 10.1 & 152.0 & 183.0 & 5.9 & 15 \\
\hline \multirow[t]{2}{*}{ Body, width ${ }^{a}$} & 90.2 & 12.5 & 80.0 & 102.2 & 13.8 & 23 \\
\hline & 100.4 & 6.0 & 93.3 & 112.0 & 6.0 & 15 \\
\hline \multirow[t]{2}{*}{ Somatic ciliary rows, ventral side, number } & 52.7 & 3.7 & 48 & 58 & 7.0 & 14 \\
\hline & 46.2 & 5.4 & 35 & 56 & 11.6 & 10 \\
\hline \multirow[t]{2}{*}{ Somatic ciliary rows, dorsal side, number } & 52.5 & 2.6 & 50 & 58 & 4.9 & 14 \\
\hline & 48.8 & 3.6 & 42 & 57 & 7.4 & 10 \\
\hline \multirow[t]{2}{*}{ Excretory pores, number } & 1.1 & 0.3 & 1 & 2 & 27.2 & 20 \\
\hline & 1.0 & 0 & 1 & 1 & 0 & 20 \\
\hline \multirow[t]{2}{*}{ Macronucleus, length ${ }^{\mathrm{b}}$} & 48.5 & 5.5 & 35.0 & 60.0 & 11.3 & 17 \\
\hline & 52.3 & 5.2 & 45.0 & 60.0 & 9.9 & 12 \\
\hline \multirow[t]{2}{*}{ Macronucleus, width ${ }^{b}$} & 23.2 & 3.9 & 17.3 & 29.2 & 16.6 & 17 \\
\hline & 28.4 & 5.0 & 20.0 & 40.0 & 17.6 & 12 \\
\hline \multirow[t]{2}{*}{ Micronucleus, number } & 2.2 & 0.8 & 1 & 3 & 35.5 & 38 \\
\hline & 2.3 & 0.6 & 1 & 3 & 27.8 & 10 \\
\hline \multirow[t]{2}{*}{ Micronucleus, length ${ }^{\mathrm{b}}$} & 3.4 & 0.6 & 2.5 & 5.0 & 17.1 & 18 \\
\hline & 3.9 & 1.2 & 3.0 & 6.5 & 32.4 & 10 \\
\hline \multirow[t]{2}{*}{ Micronucleus, width ${ }^{b}$} & 2.6 & 0.2 & 2.3 & 3.0 & 8.2 & 18 \\
\hline & 2.5 & 0.3 & 2.5 & 3.0 & 12.6 & 10 \\
\hline
\end{tabular}

Morphometric data for the type population of Frontonia paravernalis sp. nov. from Serchio Italy (IPSal + sm) are shown in bold (upper row). Morphometric data for F. paravernalis population from Peterhof, Russia (FSPBsm), are shown in normal font (lower row)

$\bar{X}$ Arithmetic mean, SD Standard deviation, Min Minimum, Max Maximum, CV Coefficient of variation in percentage, $n$ Number of investigated cells ${ }^{\mathrm{a}}$ Data based on Chatton-Lwoff silver-stained cells

${ }^{\mathrm{b}}$ Macro- and micronuclei were measured from Feulgen-stained ciliates. Measurements in $\mu \mathrm{m}$

Some other inclusions of different size and nature such as food vacuoles with bacteria, diatoms and dinoflagellates were usually present in the cytoplasm of ciliates freshly isolated from native population.

Besides the stained nuclear apparatus and Chlorellaalgae nuclei, in many cells of the Italian population of $F$. paravernalis treated for Feulgen reaction, a number of positive particles with variable size $(0.5-2.0 \mu \mathrm{m})$ were observed. They were distributed in the cytoplasm, first of all beneath cortex in the anterior and posterior ends of the ciliate (Fig. 4a, b). Apparently, the same inclusions were visible in TEM sections (Fig. 5a, c), where they appear encircled by a membrane and show inner structures delimited by membranes as well. These inclusions did not resemble bacteria according to their morphology and did not show positive signal to alphaproteobacterial and eubacterial probes during fluorescence in situ hybridization (FISH) (Fig. 5d, e), leading to the hypothesis that they were not prokaryotic endosymbionts.

\section{Biology}

In the native environment cells of $F$. paravernalis appeared mainly concentrated on the surface or slightly beneath of bottom sediments but were always present in pelagic zone as well. In both populations (Italian and Russian), ciliates mainly swam rotating to the right with respect to the longitudinal body axis; rarely a switch to the left spiral rotation was observed. Under laboratory conditions the Italian population cells showed no clear light-positive reactivity. Resting cysts were not observed. We did not succeed to keep the ciliate in culture using the dinoflagellate Peridinium sp. as food as indicated by UK colleagues, who cultivated the species they referred to as " $F$. vernalis" in the laboratory [33].

In IPSal+sm population of $F$. paravernalis conjugation process was repeatedly observed under laboratory conditions. As conjugated pairs for cytological investigation were isolated from population, we have no knowledge of the mating type system of the species. However, the main steps of the sexual process were investigated using Feulgen stained preparations (Fig. 5f-j). Three progamic divisions of Mi with crescent stage were revealed. Then, the new nuclear apparatus was rebuilt after three metagamic divisions in which from synkaryon usually developed $4 \mathrm{Ma}$ (sometimes 5-6) anlagens as well as $4 \mathrm{Mi}$. The fragmentation process of the old Ma usually started pretty late, after separation of partners and even after 
the first synkaryon division. Before the process, the old Ma changed its shape to very characteristic spindle-like form and, after separation of the partners, to twistedsausage shape. The old Ma was fragmented usually into about 8-18 fragments (Fig. 5h-j).

\section{Molecular identification}

The 18S rDNA sequences of $F$. paravernalis [MT040839 (population IPSal+sm), and MT040838 (population FSPBsm)] resulted identical among each other and showed the highest identity with sequences of $F$. shii (MF279208) and "F. vernalis" (U97110): 99.1 and 99.0\%, respectively (Table 3). Moreover, they showed $99.0 \%$ identity with $F$. vernalis from present study (one gap and 15 mismatches).

\section{Neotypification of Frontonia leucas based on IPBG population from Italy}

Frontonia leucas (Ehrenberg, 1833) Ehrenberg, 1838

\section{Diagnosis based on the IPBG population from Pisa (Italy)}

Size after silver staining $130-210 \times 60-95 \mu \mathrm{m}$; cytostome/body length ratio: $1 / 7$; $98-110$ somatic kineties; Ma: $35-50 \times 15-40 \mu \mathrm{m}$ in size; Mi: 2-3, compact-type, $3.0-5.0 \times 2.5-4 \mu \mathrm{m}$ in size; peniculi: $5+5+5$; VKs: 3 ; PKs: 5-6; PM: single-rowed; CV: single, with 8-11 canals; PCV: single, large; pigment granules absent; no cysts found; swimming rotation mainly to the right (only sometimes to the left). Freshwater.

\section{Neotype locality}

Freshwater pond in Botanical Garden of University of

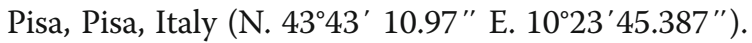

\section{Neotype material}

The slide with the silver-stained neotype specimen (indicated with a black circle of ink on the coverslip) has been deposited in the collection of the 'Museo di Storia Naturale dell'Università di Pisa' (Calci, Pisa, Italy), with registration number CAMUS_2020-5.

\section{Voucher material}

The 18S rDNA sequence of $F$. leucas resulted $1631 \mathrm{bp}$ long and was already deposited in NCBI GenBank database under the accession number AM072622 [9]. It showed the highest identity with the sequences of " $F$. angusta" (MG456580) and F. leucas from India (KY855558): 99.9 and 99.5\% respectively (Table 3).

\section{Morphological description of neotype population of Frontonia leucas}

Italian population, IPBG (Supplementary Figure 2). Cell shape ovoid with both rounded anterior and posterior end in vivo (Suppl. Fig. 2a, b). Cells dorso- ventrally flattened. Size $220 \times 95 \mu \mathrm{m}$ on average $\mu \mathrm{m}$ in vivo. Size after silver staining $130-210 \times 60-95 \mu \mathrm{m}$. Length:width ratio close to $2: 1$. Somatic cilia about $10 \mu \mathrm{m}$ long; caudal cilia sometimes slightly longer. Somatic ciliary rows, around 98-110, visible in silver stained cells (Suppl. Fig. 2e, f). Some ventral ciliary rows (especially in the posterior part of the left side) terminating before the end of the body, approaching the postoral suture. Postoral suture conspicuous, running almost to the posterior pole of the body, consisting of some empty spaces from the right side and twisted argentophilic fold in the pellicle from the left side. Cytoproct, blending into this fold, difficult to detect. On the dorsal side, not visible postoral suture (Suppl. Fig. 2f).

Preoral suture presenting an empty space going on, from upper side of buccal aperture to the rightanterior part of dorsal side (Suppl. Fig. 2f, g). In the dorsal side, several kinetosomal rows (5-6), beneath the preoral suture end, travelling parallelly to each other, with an angle of $45^{\circ}$ respect with the longitudinal axis of cell (Suppl. Fig. 2f, g). On the left, in the middle of dorsal side, 2-3 kineties tightly close to each other, forming a visible longitudinal strip in the kinetome (Suppl. Fig. 2f).

Basal bodies: on the ventral side (around the oral region) consisting of dikinetids; in the dorsal side consisting of monokinetids. Kinetosomes of oral region forming triplets after impregnation: dikinetids + parasomal sacs.

Buccal apparatus, $1 / 7$ of body length, about $28 \mu \mathrm{m}$, located on the ventral side, about $15 \%$ back from anterior body end (Suppl. Fig. 2a, e). Peniculi showing (I + II + III) $5+5+5$ rows of cilia (Suppl. Fig. $2 \mathrm{~h}$ ); from the right side, the buccal cavity presenting a single-rowed PM, closely associated with the first VK (Suppl. Fig. 2h). Three VKs, gradually elongating posteriorly from left to right (Suppl. Fig. 2h). PKs, 5-6, gradually shortening from the left posterior angle of buccal cavity to postoral suture (Suppl. Fig. 2h). Single CV with 8-11 long and twisted collecting canals, situated in the right part of the dorsal side, in the equator of the cell (Suppl. Fig. 2f).

Numerous resting spindle-shaped extrusomes (trichocysts), about $8 \mu \mathrm{m}$ long and $1.5 \mu \mathrm{m}$ wide, with a conical arrowhead-like tip, and a rounded cross-section; similar to those of Paramecium or majority of other frontoniids. $\mathrm{Ma}$ in mid-body position; always ellipsoidal, 35-50 $\times$ $15-40 \mu \mathrm{m}$ in size, after Feulgen staining (Suppl. Fig. 2b, d). Two to three compact-type Mi (commonly three) $3.0-5.0 \times 2.5-4 \mu \mathrm{m}$ in size after Feulgen staining, usually located close to the Ma (Suppl. Fig. 2c, d). Pigment granules absent. Resting cysts not observed. Swimming rotation mainly to the right, rarely to the left, with respect to the longitudinal body axis. 
Diagnosis of other retrieved frontoniids

Frontonia leucas population KNP3 (Kolleru Lake, Andhra Pradesh, India, freshwater)

Size after silver staining $134-191 \times 99-157 \mu \mathrm{m}$; cytostome/body length ratio: 1/6; 90-108 somatic kineties; Ma: $25-36 \times 11-29 \mu \mathrm{m}$ in size; Mi: 2-4, compact-type, 1.5-2.0 $\mu \mathrm{m}$ in size; peniculi: $5+5+5$; VKs: 3; PKs: 6; $\mathrm{CV}$ : single, with 7-8 canals; PCV: 1 , large; no pigment granules; no cysts found; during swimming it can rotate in both directions, but mainly to the left. The $18 \mathrm{~S}$ rDNA sequence of $F$. leucas resulted $1707 \mathrm{bp}$ long and was deposited in NCBI GenBank database under the accession number (KY855558). It showed the highest identity with sequences of F. leucas (AM072622), and "F. angusta" (MG456580): 99.5, and 99.4\%, respectively (Table 3).

\section{Material deposition}

Slide "UNIPI_2020-1" with Feulgen-stained specimens (indicated with black circles of ink on the coverslip). The slide has been deposited in the collection of the Anthropology-Zoology Unit, Department of Biology, University of Pisa, (Pisa, Italy).

\section{Frontonia paramagna populations KTC4 and KKR19 (Kolleru Lake, Andhra Pradesh, India, freshwater)}

Size after silver staining 270.2-322.0 $\times 121.8-$ $158.9 \mu \mathrm{m}$; cytostome/body length ratio: $1 / 10 ; 166-208$ somatic kineties; Ma: $63.8 \times 30.6 \mu \mathrm{m}$ in size; Mi: $6-14$, compact-type, $1.5-2.3 \mu \mathrm{m}$ in size; peniculi: $4+4+4$; VKs: 3; PKs: 6-7; CV: 1-4, with 10-14 canals; PCV: 1-3; no pigment granules; no cysts found; during swimming it can rotate in both directions (i.e., left and right). The $18 \mathrm{~S}$ rDNA sequences of $F$. paramagna populations KTC4 and KKR19 resulted 1709 bp and $1708 \mathrm{bp}$ long, respectively, and were deposited in NCBI GenBank database under the accession numbers KY855557 and KY855554, respectively. They showed the highest identity with the sequences of $F$. paramagna-MF279207 and F. paramagna-JQ868786 (type sequence of the species): 100 and 99.9\%, respectively (Table 3 ). Identical sequences were obtained from frontoniid populations BDM3, KT1, and GVMC17 sampled in India (deposited in NCBI GenBank database under the accession numbers: MT040847, MT040848, MT040849, respectively), although no morphological data are available for them.

\section{Material deposition}

Slide "UNIPI_2020-2" with silver-stained voucher specimens (indicated with black circles of ink on the coverslip). Slide "UNIPI_2020-3" with Feulgen-stained voucher specimens (indicated with black circles of ink on the coverslip). Slides have been deposited in the collection of the Anthropology-Zoology Unit, Department of Biology, University of Pisa, (Pisa, Italy).

\section{Frontonia vesiculosa population KP2 (Gosthani River, Andhra Pradesh, India, freshwater)}

Size after silver staining $450-700 \times 200-250 \mu \mathrm{m}$; cytostome/body length ratio: $1 / 10 ; 150-180$ somatic kineties; Ma: $70-90 \times 30-50 \mu \mathrm{m}$ in size; Mi: 8-12, compact-type, 3.5-4.5 $\mu \mathrm{m}$ in size; peniculi: $5+5+5$; VKs: $3-4$; PKs: $6-$ 7; CV: 7-11, with 12-15 canals; PCV: 1-2; permanent pigment granules absent; no cysts found; during swimming it can rotate in both directions (i.e., left and right). The $18 \mathrm{~S}$ rDNA sequence of $F$. vesiculosa resulted 1708 bp long and was deposited in NCBI GenBank database under the accession number (MT040850). It showed the highest identity with sequences of $F$. paramagna (MF279207, JQ868786, and those from present study): 99.4\% (Table 3).

\section{Frontonia sp. population IPSal- (Serchio River, Italy, freshwater)}

Size after silver staining $145-200 \times 70-105 \mu \mathrm{m}$; cytostome/body length ratio: 1/8; 92-105 somatic kineties; Ma: $30-45 \times 15-30 \mu \mathrm{m}$ in size; Mi:1-3, compact-type, 3.0-3.2 $\mu \mathrm{m}$ in size; peniculi: $5+5+5$; VKs: 3 ; PKs: $6-$ 7; CV: single, with 9-11 canals; PCV: one in the dorsal side; pre-suture is continue on the dorsal side; no pigment granules; no cysts found; during swimming it mainly rotates to the right, and less frequently to left direction. The $18 \mathrm{~S}$ rDNA sequence of Frontonia sp. IPSal- resulted $1708 \mathrm{bp}$ long and was deposited in NCBI GenBank database under the accession number (MT040841). It showed the highest identity with the sequence of Frontonia sp. (AF255359): 99.8\% (Table 3). An identical sequence was obtained from Frontonia sp. population VmFr, sampled in Sardinia (Monte Urpino Park, Cagliari, Italy) (deposited in NCBI GenBank database under the accession number MT040842), although no morphological data are available for this population.

\section{Frontonia atra population F4 (Serchio River, Italy, freshwater)}

Size after silver staining $80-100 \times 40-50 \mu \mathrm{m}$; cytostome/ body length ratio: $1 / 4$; 80-90 somatic kineties; Ma: $15-$ $25 \times 15-20 \mu \mathrm{m}$ in size; Mi: $1-2$, vesicular-type, $2.5-3.5 \mu \mathrm{m}$ in size; peniculi: $4+4+3$; VKs: 4; PKs: 4; CV: single, without canals; PCV: 2-4; pigment granules present; no cysts found. The 18S rDNA sequence of $F$. atra resulted 1663 bp long and was deposited in NCBI GenBank database under the accession number (MT040844). It showed the highest identity with sequences of $F$. minuta (MT040846) and an uncultured ciliate (AY821929): 98.6 and 98.2\%, respectively (Table 5). 


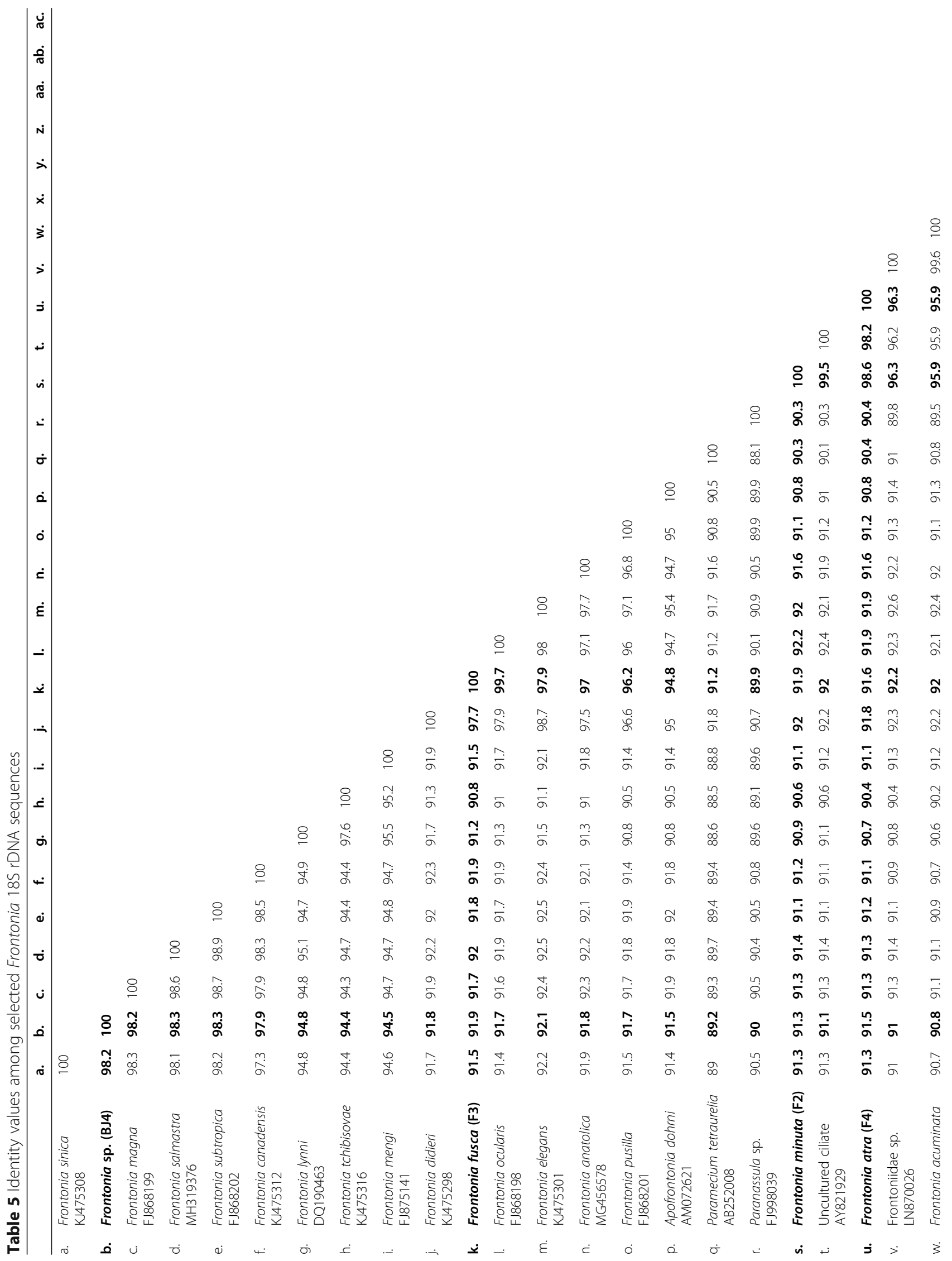




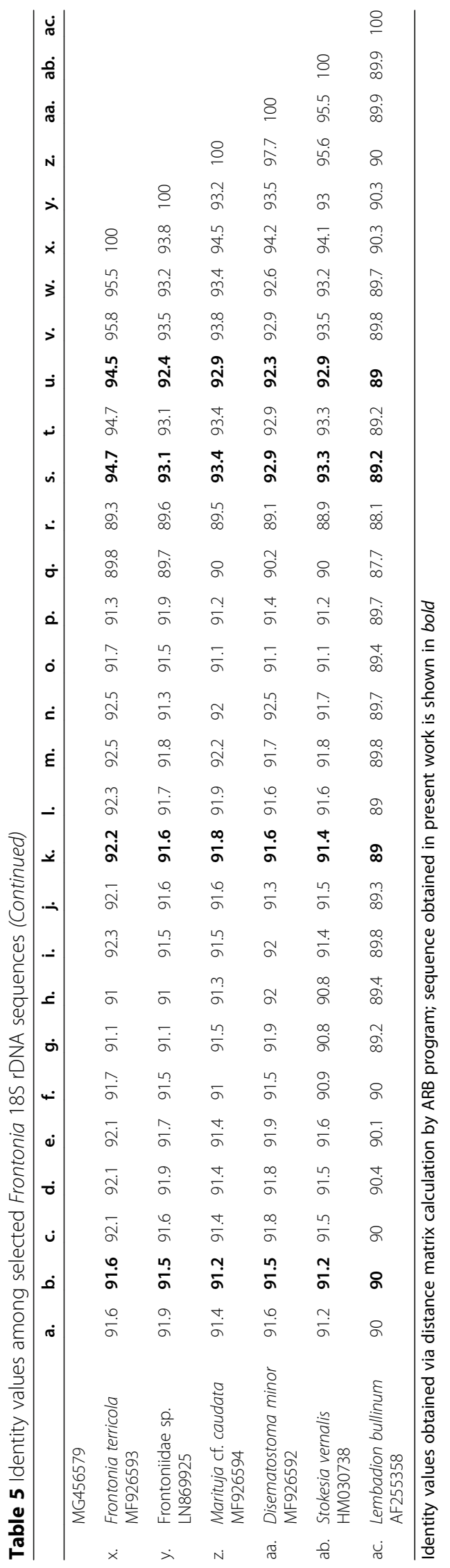




\section{Frontonia minuta population F2 (Serchio River, Italy, freshwater)}

Size after silver staining $60-90 \times 40-60 \mu \mathrm{m}$; cytostome/body length ratio: $1 / 5 ; 50-65$ somatic kineties; Ma: $15-20 \times 10-15 \mu \mathrm{m}$ in size; Mi: two, endosomaltype, $1.5-2.0 \mu \mathrm{m}$ in size; peniculi: $4+4+3$; VKs: $3-4$; PKs: 3-4; CV: single, without canals; PCV: 2-4; no pigment granules; extrusomes relatively long with respect to ciliate size; no cysts found. The $18 \mathrm{~S}$ rDNA sequence of $F$. minuta resulted $1663 \mathrm{bp}$ long and was deposited in NCBI GenBank database under the accession number (MT040846). It showed the highest identity with sequences of an uncultured ciliate (AY821929) and F. atra (MT040844): 99.5 and 98.6\%, respectively (Table 5 ).

\section{Frontonia fusca population F3 (Serchio River mouth, Italy, brackish water: salinity 14\%o)}

Size after silver-staining 90-150 $\times 45-70$; cytostome/ body length ratio: $1 / 5$; 75-92 somatic kineties; Ma: 25-35 $\times 20-25 \mu \mathrm{m}$ in size; Mi: $1-2$, endosomal-type, 1.5-2.0 $\mu \mathrm{m}$ in size; peniculi: $4+4+3$; VKs: 3; PKs: 4; PM: double-rowed; CV: two, with 6-9 canals; PCV: $2-3$, on the dorsal side; pigment granules are present as a spot on the anterior right point of dorso-lateral side; no cysts found; pre- and postoral sutures widely run on the dorsal side; during swimming it preferably rotates to the right direction [10]. The $18 \mathrm{~S}$ rDNA sequence of F. fusca resulted $1667 \mathrm{bp}$ long and was deposited in NCBI GenBank database under the accession number (MT040845). It showed the highest identity with the sequence of " $F$. ocularis" (FJ868198): 99.7\% (Table 5). The close identity and morphological affinity with " $F$. ocularis" will be further discussed below.

\section{Frontonia sp. population BJ4 (India, brackish water: salinity 5\%o)}

Size after silver staining $180-250 \times 100-150 \mu \mathrm{m}$; cytostome/body length ratio: $1 / 5 ; 113-134$ somatic kineties; Ma: $45-70 \times 20-40 \mu \mathrm{m}$ in size; Mi: 1 , compact-type, 4.3-4.6 $\mu \mathrm{m}$ in size; peniculi: $4+4+4-3$; VKs: 4-5; PKs: 4-5; PM: double-rowed; CV: single, with a net of collecting canals; PCV one in the dorsal side; no pigment granules; extrusomes rhombic in section; pre- and postoral sutures widely run on the dorsal side; no cysts found; during swimming it rotates to the left direction. The $18 \mathrm{~S}$ rDNA sequence of Frontonia sp. BJ4 resulted $1711 \mathrm{bp}$ long and was deposited in NCBI GenBank database under the accession number (MT040843). It showed the highest identity with sequences of $F$. subtropica and $F$. salmastra (98.3\%), F. sinica, and F. magna (98.2\%) (Table 5).

\section{Molecular phylogeny of Frontonia}

Phylogenetic relationships of Frontonia species presented in this study are reported in Fig. 6. As for the F. vernalis and the novel species from the present study, the topology of BI/ML tree showed that they cluster in the same clade of "F. vernalis" (U97110) and F. shii (MF279208) with quite high statistical support (0.96/86). Unfortunately, the phylogenetic relationships inside the clade were not resolved by the analysis, showing polytomies.

The genus Frontonia appeared to be not monophyletic. Four clades can be distinguished, with the following species composition: Clade 1: F. sinica, F. magna, F. salmastra, F. subtropica, F. canadensis, F. tchibisovae, F. lynni, F. mengi, and Frontonia spp.; Clade 2: F. paramagna, F. vesiculosa, "F. vernalis", F. shii, F. vernalis (present study), F. paravernalis, F. leucas, "F. angusta" and Frontonia spp.; Clade 3: F. didieri, "F. ocularis", F. elegans, F. fusca, F. anatolica, and F. pusilla; Clade 4: F. acuminata, F. minuta, F. atra, F. terricola, and uncultured frontoniids (AY821929, LN870026, LN869925).

Clade 1 and Clade 2 resulted sister clades, forming a monophyletic group with high statistical support, i.e., $1.00 / 100$. In the molecular tree, the position of the sequences of "F. leucas" (MG437395-96) in Clade 1, and "F. angusta" (MG456580) in Clade 2, is questionable and will be later discussed, since the species attribution made by Kizildag and Yildiz [25] in our opinion should be revised (i.e., the morphological description of these two species diverges from the original descriptions of F. leucas sensu Ehrenberg and Foissner and F. angusta sensu Foissner).

Clade 3 appeared sister of Apofrontonia dohrni, and they (Clade $3+$ Apofrontonia) together resulted sister group of Paramecium (1.00/96).

Clade 4 grouped together with sequences of Marituja, Disematostoma, Stokesia: in this group, evolutionary relationships were not resolved, showing polytomies.

Peniculia group members (Frontonia, Apofrontonia, Paramecium, Paranassula, Stokesia, and Lembadion) clustered together showing high values of statistical support (1.00/100).

The sequence of Frontonia sp. BJ4, branched basally to F. sinica - F. magna - F. salmastra - F. canadiensis - F. subtropica - clade, with high statistical support (1.00/ 100), inside Clade 1.

Sequences of F. paramagna (LT628495, KY855554, KY855559, MT040847-49) clustered with conspecifics, including the type sequence of the species (JQ868786), inside Clade 2. Since sequences under the name " $F$. leucas" (MG437395-6) clustered in the same F. paramagna-clade (significantly far from the type sequence of F. leucas - AM072622), we strongly believe that those organisms were misidentified (see Discussion section). 
- $\mathrm{BI} / \mathrm{ML}=1.00 / 100$

Frontonia sinica KJ475308

Frontonia sp. FJ870102

Frontonia sp. FJ870102
Frontonia magna FJ876953
Frontonia magna FJ868199

$\mathrm{BI} / \mathrm{ML}<0.80 / 75$ 0.921- $\quad 0$ - Frontonia salmastra MH319376

- $\quad$ Frontonia canadensis FJ868196

0.91/- 0.86/95 Frontonia canadensis KJ475312

Frontonia sp. HM140397

1.00/98 Frontonia subtropica FJ868202

-Frontonia sp. (BJ4) MT040843

- Frontonia lynni DQ190463

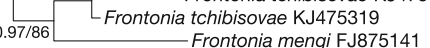

"Frontonia leucas" MG437395

Frontonia paramagna (ML) LT628495

Frontonia paramagna (KTC4) KY855559

0.97/- Frontonia paramagna (KKR19) KY85555

Frontonia paramagna (KT1) MT040848

Frontonia paramagna (GVMC17) MT040849

Frontonia paramagna (BDM3) MT040847

0.82/98 [Frontonia paramagna (type sequence) JQ868786

1.00/89 Erontonia paramagna MF279207

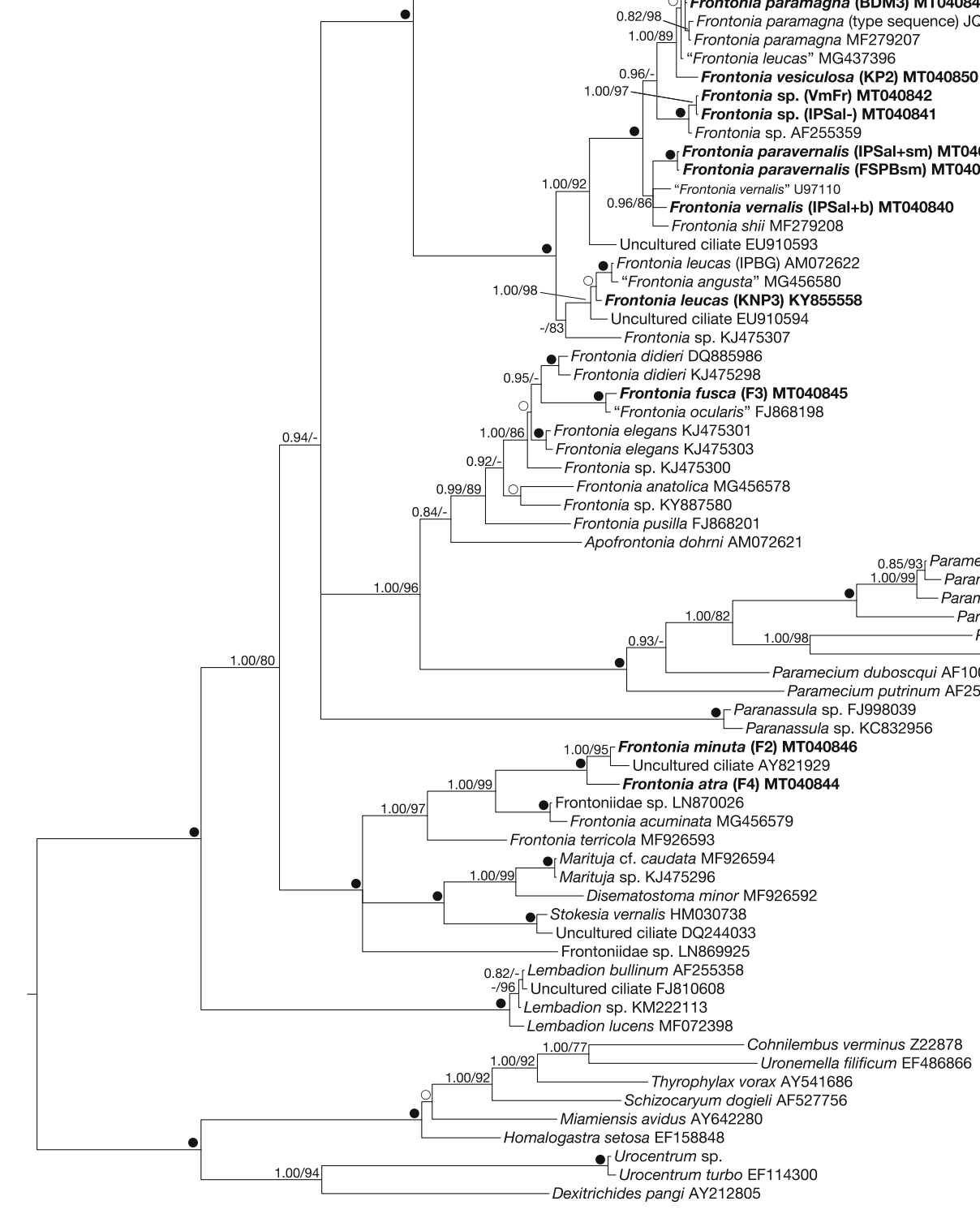

Frontonia

Clade 2

Frontonia

Clade 1

(

Frontonia sp. (IPSal-) MT04084

onia sp. AF25535

nia vernalis" U97110

MTm) MT040838

Frontonia

Clade 3

OUTGROUP

other

Oligohymenophorea

Fig. 6 (See legend on next page.) 
(See figure on previous page.)

Fig. 6 Phylogenetic tree of the subclass Peniculia based on 18S rDNA sequences. Phylogenetic relationships of Frontonia vernalis (neotype) and Frontonia paravernalis sp. nov.: they cluster in the same clade of "F. vernalis" and F. shii. Phylogenetic position of the other Frontonia spp. in analysis is shown as well. Genus Frontonia resulted paraphyletic, forming four different clades (Clade1-4). Numbers associated to nodes represent posterior probability from Bayesian inference $(\mathrm{Bl})$ and bootstrap value from maximum likelyhood $(\mathrm{ML})$ analyses, respectively (only values of $\mathrm{BI}>$ 0.80 and $M L>75 \%$ are shown). Black dots represent the highest statistical support $(B I=1.00$ and $M L=100)$; white dots indicate non-significant statistical support $(\mathrm{BI}<0.80$ and $\mathrm{ML}<75)$. Sequences obtained in the present work are in bold

Sequence from $F$. vesiculosa (MT040850) resulted the sister species of $F$. paramagna.

Sequences from IPSal- and VmFr Frontonia sp. clustered together with Frontonia sp.-AF255359, forming a clade sister to $F$. paramagna $+F$. vesiculosa. These two populations (IPSal- and $\mathrm{VmFr}$ ) constitute, to the best of our knowledge, a novel Frontonia species.

Sequence of F. leucas KNP3 (KY855558) branched basally to the type sequence of $F$. leucas (AM072622). In this clade, the sequence indicated as "Frontonia angusta" (MG456580), clustered with the type sequence of F. leucas: in our opinion some error or misidentification occurred (see Discussion section).

Frontonia fusca's sequence (MT040845) clusters together with $F$. ocularis sequence, in Clade 3. Given the morphological and phylogenetic affinity between the two organisms we are prone to consider them as the same species, thus following the Principle of Priority of the ICZN (Article 23) we keep as valid F. fusca (Quennerstedt, 1869) Kahl, 1931. Consequently, F. ocularis described by Bullington [31] and redescribed by Pan and colleagues [14] should be treated as the junior synonym of $F$. fusca ([17], this study) and indicated at least as " $F$. ocularis".

Sequences of $F$. minuta and $F$. atra clustered in Clade 4, being sister of $F$. acuminata and an uncultured frontoniid (LN870026).

\section{Phylogeny of endosymbionts of $F$. vernalis and $F$. paravernalis sp. nov.}

The 18S rDNA sequence of the endosymbionts from the Italian population of $F$. vernalis (IPSal+b) resulted 1796 bp long and showed a high identity with several species of the family Chlorellaceae: $100 \%$ with Chlorella sp. (X72706), 99.9\% with Chlorella sorokiniana (FM205834), 99.8\% with Micractinium reisseri (endosymbiont of $P$. bursaria) (AB437244) (Table 6). It was deposited in NCBI GenBank under the accession number MT040853.

The 18S rDNA sequence of the endosymbionts of the Italian population of $F$. paravernalis (IPSal $+\mathrm{sm}$ ) resulted $1796 \mathrm{bp}$ long and identical to the one from endosymbionts of IPSal $+\mathrm{b} F$. vernalis (Table 6). Interestingly, the same species of Frontonia from Russia (FSPBsm) harboured a different kind of green endosymbiont: their $18 \mathrm{~S}$ rDNA sequences, $1758 \mathrm{bp}$ long, showed the highest identity, 99.4\%, with Meyerella planktonica (AY195973) and Chlorella sp. symbiont of Hydra sp. (AB713410, AB713408). The identity with the sequences of endosymbionts of Italian F. paravernalis resulted 98.9\% (Table 6). If compared with the 18S rDNA sequence from the green endosymbiont of $P$. chlorelligerum (KX669637) found in the same sampling site in St. Petersburg [41], our endosymbiont's sequence showed an identity of $99.0 \%$ (that sequence was not used in our phylogenetic reconstruction because too short). The $18 \mathrm{~S}$ rDNA sequences of endosymbionts of $F$. paravernalis were deposited in NCBI GenBank under the accession numbers MT040852 (population IPSal+sm from Italy), MT040851 (population FSPBsm from Russia).

In our phylogenetic analysis the $18 \mathrm{~S}$ rDNA sequences of endosymbionts from Italian populations of Frontonia (F. vernalis IPSal $+\mathrm{b}$, F. paravernalis IPSal $+\mathrm{sm}$ ) clustered significantly far respect with those from the Russian population (F. paravernalis FSPBsm) (Fig. 7). Indeed, endosymbionts from Italian frontoniids resulted close to some species of Chlorella, such as C. sorokiniana (LK021940), and Chlorella sp. (X72706), while endosymbionts from Russian F. paravernalis clustered with Meyerella planktonica (AY195973, AY543042, AY543039), with median statistical values (0.97/78). Moreover, sequences from symbionts of Hydra branched basally to the Meyerella-Frontonia's endosymbiont-clade (statistical support: 1.00/94).

Beyond that, no other symbiotic Chlorella-like organisms did show any special phylogenetic affinity with our sequences. However, the phylogenetic relationships inside the Chlorella-clade were not completely resolved, and several polytomies occurred (Fig. 7). This might indicate a low-resolution power of the $18 \mathrm{~S}$ rDNA as marker to study the phylogenetic relationships of this group of organisms.

\section{Discussion}

The Frontonia vernalis issue and its neotypyfication Freshwater frontoniids hosting Chlorella-like cytoplasmic symbionts were repeatedly mentioned in the ciliatological literature since when Ehrenberg described one such ciliate under the name of $F$. vernalis $[29,30]$. He found this species in the neighbourhood of Berlin and he gave the following diagnosis: "Corpore ovato oblongo turgido, viridi, utrinque rotundato, postica parte paullo tenuiore, ore tertia quartave corporis parte superato" 


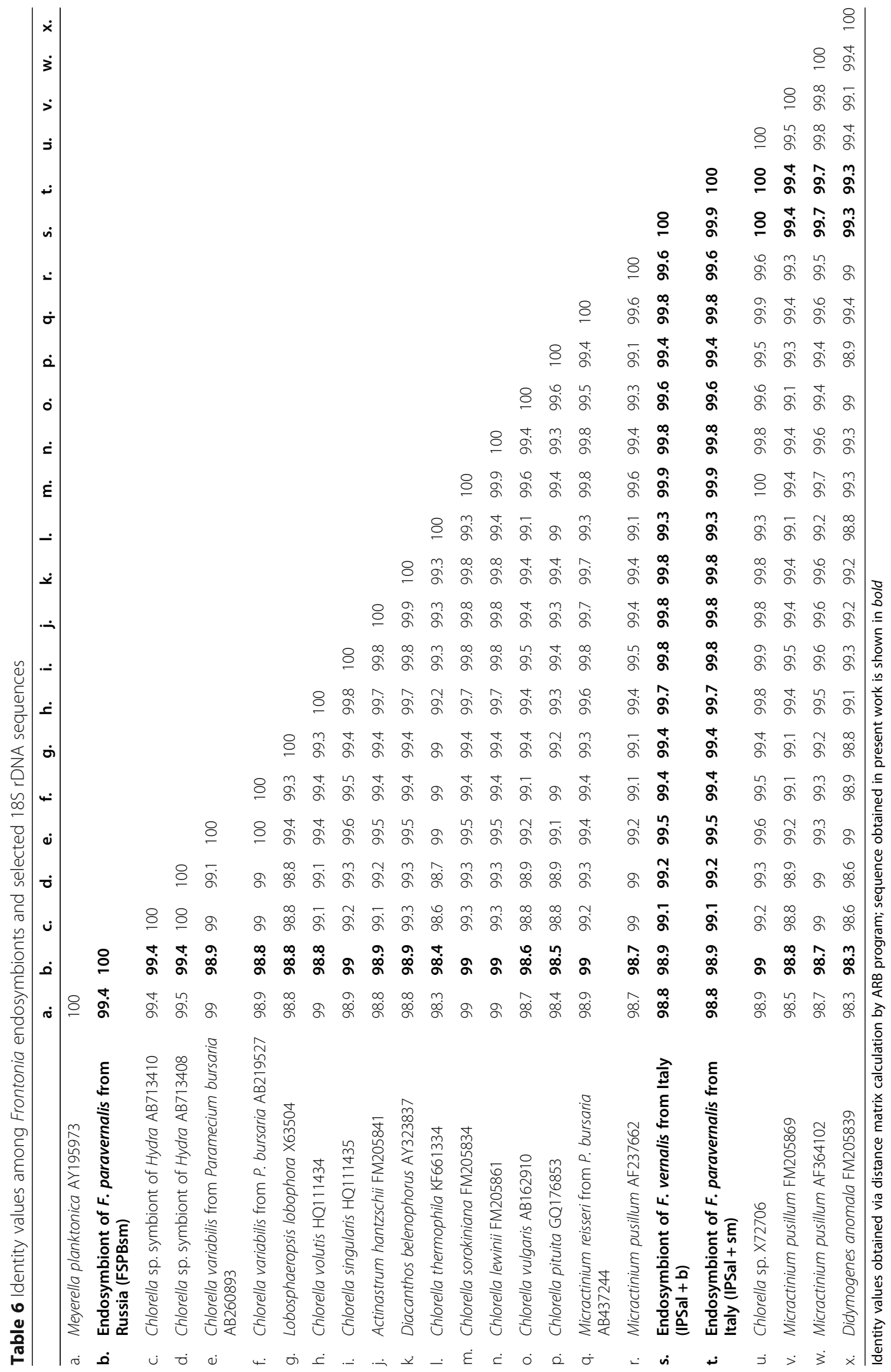




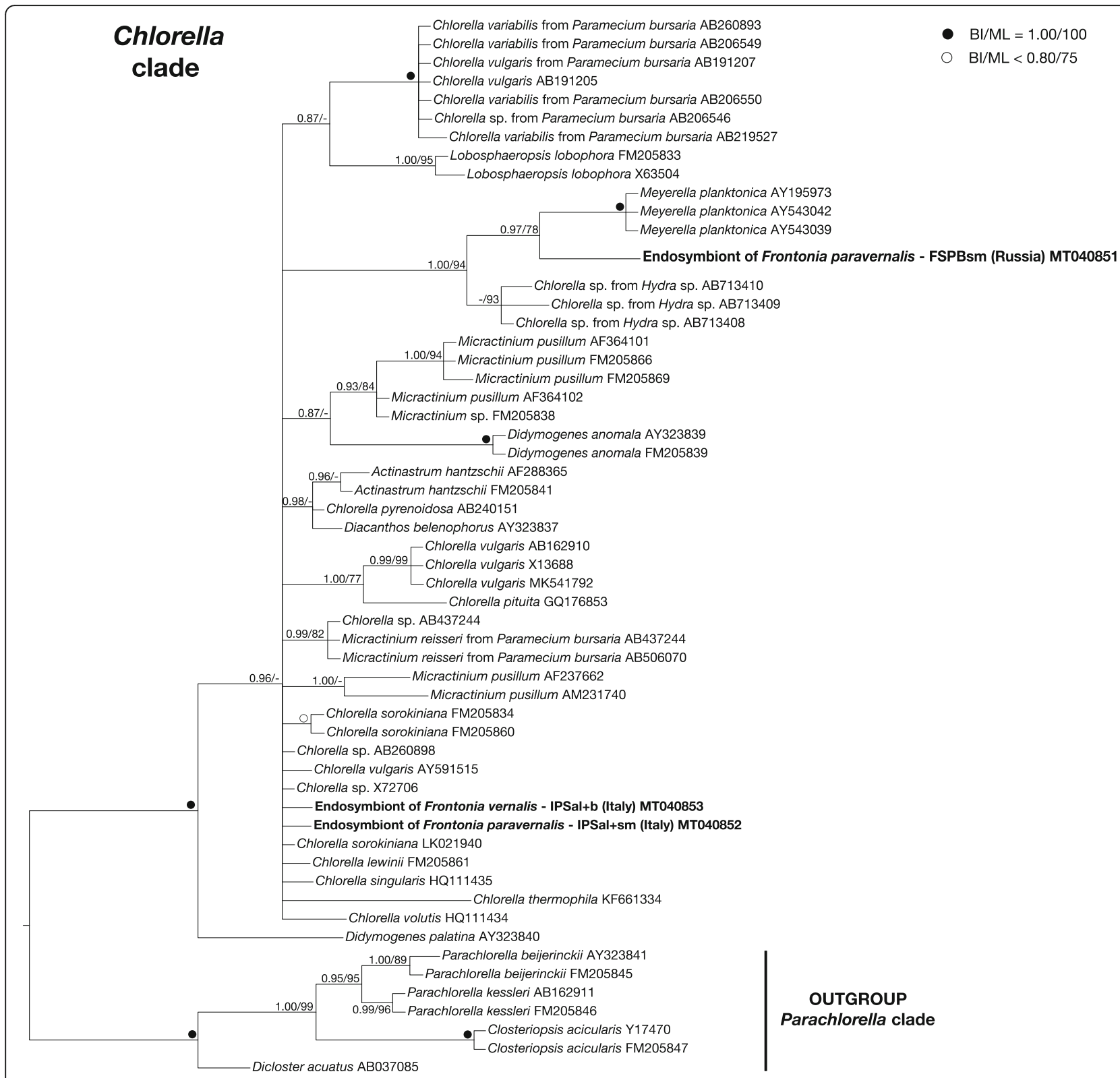

0.002

Fig. 7 Phylogenetic tree of the Chlorella clade based on 185 rDNA sequences. Phylogenetic relationships of endosymbionts from Italian and Russian population of Frontonia paravernalis sp. nov. (IPSal+sm, FSPBsm) and from Italian population of Frontonia vernalis (IPSal+b) are shown. Endosymbionts from the same Frontonia species (IPSal+sm, FSPBsm - Italian and Russian F. paravernalis) cluster relatively far from each other, instead endosymbionts from the same site (Italy) cluster together, although they are hosted by different species ( $F$. paravernalis - IPSal+sm and $F$. vernalis - IPSal+b). Numbers associated to nodes represent posterior probability from Bayesian inference (BI) and bootstrap value from maximum likelyhood (ML) analyses, respectively (only values of $\mathrm{BI}>0.80$ and $\mathrm{ML}>75 \%$ are shown). Black dots represent the highest statistical support $(\mathrm{Bl}=$ 1.00 and $M L=100$ ); white dots indicate non-significant statistical support $(B \mathrm{~B}<0.80$ and $M L<75)$. Sequences obtained in the present work are in bold

["Oval-oblong body, swollen, green, rounded at both ends, narrowed behind, mouth located in the apical third quarter of the body] [30]. He described this species as 211-254 $\mu \mathrm{m}$ long, carrying two CVs which, actually, together with the ciliate's Ma, he misidentified as the male reproductive system of the "animal" ("Eine grosse ovale männliche Sexualdrüse and 2 runde contractile Blasen bilden den männlichen Geschlechtsorganismus" [The large oval male genital gland and two round contractile bladders form the male sexual apparatus]).

Later, Dujardin [43] mentioned F. vernalis (referred to as Panophrys (Bursaria) vernalis), however, he simply 
reported the description previously made by the German scientist. Thus, since Ehrenberg's record, no other scientist was able to retrieve the ciliate corresponding to the descriptions made in 1833 and 1838. Although, later on, a green frontoniid was retrieved and identified as $F$. vernalis by UK researchers [33-35], its appearance was not completely fitting with that made by Ehrenberg (in particular it showed only a single CV vs. two CVs described by Ehrenberg). Unfortunately, our requests to UK colleagues to provide us with more precise information about the morphology of that Frontonia species ("F. vernalis") have been ignored.

However, some doubts on the accuracy of Ehrenberg's description can be expressed as well. For instance, Ehrenberg did not indicate the number of investigated cells. Moreover, in both publications (i.e., [29]: Plate III Fig. IV, and [30]: Plate XXXIV - Fig. VII) he used the same illustrations, showing three different cells of $F$. vernalis (one of the cells appeared crushed in the version dated 1833). In the latest publication [30], the Author provided an additional image of $F$. vernalis, showing two larger specimens plus a significantly smaller third cell. Considering these three complete ciliate's images (Fig. 1), two of them possess two CVs without canals (larger cells), while in the third cell only a single CV with canals is visible $[29,30]$. Therefore, it is difficult to cope with such uncertain data about the number of CVs in the type description of $F$. vernalis (i.e., it is challenging to confidently address the question "does the species always possess two CVs?").

It must be stressed that the Author illustrated a conjugating couple ([29]: Plate III-Fig IV [30];: Plate XXXIV, Fig VII) (Fig. 1) describing it as a "dividing" specimen. In our opinion, according to his statements ["Einige Thierchen fand ich in der Längstheilung begriffen": "I found some animals in the process of longitudinal division"] he probably never observed a division process in the retrieved green frontoniids, which actually takes place along the transverse cell axis as typical of ciliates. Very likely, Ehrenberg saw some specimens in a predividing phase (indeed, he selected two large cells), although without recognizing them as such. Given the fact that in peniculine ciliates CV duplicates before cell division, this could explain why Ehrenberg detected two of such organelles.

Therefore, we can hypothesize different scenarios about the description of $F$. vernalis and its real morphology: i) Ehrenberg detected a mixed population of green frontoniid species, one with two CVs plus another carrying only a single $\mathrm{CV}$, i.e., $F$. vernalis possesses two $\mathrm{CVs}$ and has never been found again; ii) Ehrenberg detected a green frontoniid species which presented variability in its $\mathrm{CV}$ number, i.e., F. vernalis possesses either one or two CVs; iii) Ehrenberg described a green frontoniid species in a pre-division stage, i.e., F. vernalis possesses one CV and the description made by Ehrenberg should not be considered valid concerning this particular trait.

In our opinion, the first two hypotheses can be considered rather unlikely, because i) if existing, green Frontonia with two CVs should have been found again, at least another time; ii) variability of CV number in a Frontonia species is a quite rare event:the number of CVs is a stable feature for almost all frontoniids except for $F$. vesiculosa, $F$. paramagna, which present several CVs ([20], present study), and for F. betica [44] and F. magna [13], which may present one or two CVs.

In conclusion, after this careful consideration of all aspects, we are prone to consider more reliable the third hypothesis, and we propose the neotypification of $F$. vernalis, based on the green frontoniid retrieved in Italy (population IPSal+b). This species basically possesses all the (few) characteristics mentioned by Ehrenberg except the presence of two CVs: body size and shape are comparable (length: $220-300 \mu \mathrm{m}$ vs. $211-254 \mu \mathrm{m}$ ), both species were retrieved in freshwater habitats and present Chlorella-like endosymbionts.

Moreover, the $18 \mathrm{~S}$ rDNA sequence of the newly retrieved $F$. vernalis shows a high identity value with " $F$. vernalis" - U97110 sequence (Hirt and colleagues, 1997), although not being completely identical.

Unfortunately, it was not possible to clearly assess whether our $F$. vernalis and the species which the U97110 sequence belongs to are identical for the following reasons: i) a morphological description associated to this sequence is lacking; ii) the U97110 sequence presents many uncertain nucleotides (6 "N", 1 "W", 1 "Y"), which makes the comparison with our retrieved sequence not so reliable.

Consequently, since an exhaustive morphological description of the organism corresponding to the sequence U97110 (Hirt and colleagues, 1997) is lacking, the latter should be only carefully used for phylogenetic reconstruction and we recommend referring to it as Frontonia sp. or as "F. vernalis".

\section{Comparison among green Frontonia species}

Green frontoniids were repeatedly sampled by ciliatologists, but often misidentified (see Background and Discussion sections above). For example, the indication that F. minuta may also harbour Chlorella-like symbionts [20] sounds rather unexpected and has never been reported again. Therefore, to date, only few green Frontonia species were correctly identified. Beside some reports of $F$. vernalis sensu Ehrenberg, only one new Frontonia species bearing Chlorella-like endosymbionts was recently retrieved and described through a multidisciplinary characterization, i.e., F. shii [15].

The species treated in the present study, F. vernalis (neotype) and $F$. paravernalis sp. nov., present 
morphological and phylogenetic affinities with this recently described species (Table 7). These three green frontoniids cluster together in our phylogenetic analysis (Fig. 6), although molecular data and morphological features clearly indicate that $F$. shii does not coincide with any of our two target species.

According to some morphological characteristics, $F$. vernalis (neotype) recalls $F$. shii, but the two species cannot be synonymised. The number of somatic kineties (120-145 vs. 128-142), the number of vestibular (3 vs. $3-4)$ and postoral kineties (6-7 vs. $7-8)$ are similar between $F$. vernalis (neotype) and $F$. shii (Table 7). However, F. vernalis (neotype) cells are smaller $(250 \times 125 \mu \mathrm{m}$ vs. $300 \times 200 \mu \mathrm{m}$ in living condition), the position of its PCV is dorsal (vs.ventro-lateral), postoral suture ends before the posterior end of the cell (vs. reaches the posterior end of the cell), and it facultatively swims rotating to the left or to the right with respect to the longitudinal body axis (i.e., rotation is clockwise and anticlockwise vs. anticlockwise rotation only). Moreover, according to description, the PM of F. shii is formed by a double-rowed structure (vs. single-rowed) although, looking at the images provided of the silver stained cells, this arrangement is not so obvious (see Fig. 2G in [15]). A set of very distinctive features is present in $F$. vernalis (neotype), such as the number and type of $\mathrm{Mi}$ and the presence of parallel kineties in the dorsal apical areas (vs. absence in $F$. shii).

According to morphology, F. paravernalis differs from F. shii, being smaller in size $(178 \times 95 \mu \mathrm{m}$ vs. $300 \times$
$200 \mu \mathrm{m}$ in living condition), showing a lower number of somatic kineties (98-116 vs. $128-142$ ), and showing different features regarding the PCV position, the PM, the postoral suture, and the swimming rotation (Table 7). Frontonia paravernalis clearly differs from $F$. vernalis (neotype) as well, showing a different combination of traits, such as the lower number of Mi (two vs. six on average), dorsal parallel kineties (6-8 vs. $8-10)$, and the presence of a fourth row of VK (vs. only three in F. vernalis from present study).

The distance among the 18S rDNA sequences of these ciliates (F. vernalis, F. paravernalis, and F. shii) corroborates morphological investigation findings, further confirming their attribution to different species: on average their sequences diverge for ten nucleotides or more, that is a rather conspicuous difference for this highly conserved molecular marker. Indeed, what we suspect is that species belonging to the green frontoniids clade would constitute a complex of species. Obviously, further molecular studies would be required to address this issue.

Comparison between morphology of Italian and Russian populations of $F$. paravernalis indicates that morphometric values are very similar among the two populations (Table 4) (mean values): body size $-159.0 \times$ $90.2 \mu \mathrm{m}$ vs. $171.7 \times 100.4 \mu \mathrm{m}$; somatic ciliature (ventral + dorsal) -105 vs. 95 ; Ma size $-48.5 \times 23.2 \mu \mathrm{m}$ vs. $52.3 \times$ $28.4 \mu \mathrm{m}$; Mi size $-3.9 \times 2.5 \mu \mathrm{m}$ vs. $3.4 \times 2.6 \mu \mathrm{m}$. The main characters present quite stable features as well: i) in cells of both populations the number of the Mi range from one to three (two on average); ii) cells possess one

Table 7 Comparative characterization of green frontoniids

\begin{tabular}{|c|c|c|c|c|}
\hline Characters & $\begin{array}{l}\text { Frontonia vernalis } \\
\text { sensu Ehrenberg }\end{array}$ & F. vernalis (Neotype) & F. paravernalis sp. nov. & F. shii \\
\hline Average body length of living cells ( $\mu \mathrm{m})$ & 233 & 250 & 178 & 300 \\
\hline Somatic kineties, number & ND & $120-145$ & $98-116$ & $128-142$ \\
\hline Contractile vacuoles, number & $1-2$ & 1 & 1 & 1 \\
\hline Collecting canals, number & ND & $8-12$ & $8-11$ & $\sim 10$ \\
\hline PCV, number, position & ND & 1, dorsal & 1, dorsal & 1, ventro-lateral \\
\hline Postoral suture silver line & ND & $\begin{array}{l}\text { Ends before the posterior } \\
\text { end of the cell }\end{array}$ & $\begin{array}{l}\text { Ends before the posterior } \\
\text { end of the cell }\end{array}$ & $\begin{array}{l}\text { Reach the posterior } \\
\text { end of the cell }\end{array}$ \\
\hline Peniculi (I + II + III) & ND & $4+4+4$ & $4+4+4$ & $4+4+4$ \\
\hline Vestibular kineties, number & ND & 3 & $3-4$ & $3-4$ \\
\hline Postoral kineties, number & ND & $6-7$ & $5-7$ & $7-8$ \\
\hline Paroral membrane & ND & $\begin{array}{l}\text { One-rowed, very close } \\
\text { to vestibular kinety }\end{array}$ & $\begin{array}{l}\text { One-rowed, very close } \\
\text { to vestibular kinety }\end{array}$ & Double-rowed \\
\hline Dorsal zone of parallel kineties & ND & $8-10$ & $6-8$ & Not applicable \\
\hline Micronucleus, number & ND & $3-9$ & $1-3$ & Not observed \\
\hline Swimming rotation & ND & $\mathrm{R} / \mathrm{L}$ & $\mathrm{R} / \mathrm{L}$ & $\mathrm{L}$ \\
\hline Reference & {$[29,30]$} & Present study & Present study & {$[15]$} \\
\hline
\end{tabular}

$N D$ No data, $L$ During swimming cell rotates to the left, $R / L$ During swimming, cell can rotate in both directions - right (predominantly) and left, $P C V$ Pore of contractile vacuole 
$\mathrm{CV}$ with one PCV; iii) the pattern of the oral ciliature is identical, i.e., consists of peniculi with four rows of kinetidies each, single-rowed PM closely associated with the first VK; 3-4 VKs; 5-7 PKs; iv) longitudinal dorsal strip of kinetids as well as structure and position of $\mathrm{CV}$ are identical (Fig. 4g, Suppl. Fig. 1).

Interestingly, algal symbionts in the investigated populations of $F$. paravernalis are molecularly different between Italian and Russian populations (see Discussion below). The nature of Feulgen-positive particles observed in the cytoplasm of cells in Italian population of F. paravernalis (Fig. 4a, c-e) remains unknown. FISH results indicate that they are not Eubacteria, and TEM observations confirmed this point; thus, further investigations are needed to solve this interesting issue.

To sum up, according to the 18S rDNA-based phylogenetic reconstruction we can treat all green frontoniids as members of the same cluster and, in our opinion, they might possibly form a complex of species given that i) from a morphological point of view all of them manifested a single CV and the symbiosis with Chlorella-like algae - indeed, we believe that the capability to host green algae as cytoplasmic symbionts should be treated as a stable feature of green frontoniids as well; and ii) they all share the freshwater environment.

\section{The Frontonia type species issue}

The type species of genus Frontonia has never been precisely designated and type material is presently lacking. As already mentioned, the first two species of Frontonia ever described were $F$. vernalis and $F$. leucas sensu Ehrenberg, firstly indicated as Bursaria [29] and then renamed after Frontonia [30].

As extensively discussed above, $F$. vernalis sensu Ehrenberg lacks a proper description and several subsequent misidentifications occurred since its first publication, suggesting that this species would not be the best candidate to became the type species of the genus.

On the other hand, neither original description of $F$. leucas sensu Ehrenberg, was exhaustive. Ehrenberg [29, 30] provided only few morphological details: F. leucas presented a single CV ("die sternf rmige contractile Blasé") and green inclusions in the cytoplasm were absent [30]. Despite these inconveniences, in our opinion, F. leucas could be the best candidate as the type species of genus Frontonia.

Foissner and colleagues provided a detailed morphological redescription of $F$. leucas [3], but unfortunately, they did not provide a type material and molecular markers for the studied ciliate. Once more in that publication F. leucas was not designated as the type species of the genus Frontonia, although it was suggested later on by another author [45].
According to literature data [3, 4], Frontonia leucas morphospecies presents a wide morphological variation, but actually, it is more likely that different species of Frontonia have been often misidentified as F. leucas, given that in phylogenetic reconstructions these organisms are located far away to each other (see for example sequences MG437395-96, in Fig. 6).

Indeed, in a very recent article dealing with the description of $F$. leucas and three additional Frontonia species isolated in Turkey with the phylogenetic reconstruction of the genus, Kizildag and Yildiz wrote: "We guessed that the identification of this sequence $[F$. leucas - AM0722622, published in [9]] might be incorrect, since the morphological data were not presented" ([25]: p. 561). In our opinion, the above sentence is even logically incorrect: the lack of specific morphological data associated to F. leucas AM0722622 in the investigation by Fokin et al. [9] actually was only due to the necessities of the research context, i.e., the study was focused on the description of Apofrontonia dohrni.

However, with the present study, we took this opportunity to integrate the molecular data (i.e., the first sequence published under the name of $F$. leucas, AM072622) with the diagnosis (morphological description plus figures) of the $F$. leucas Italian population IPBG. Therefore, we propose this population of $F$. leucas corresponding to the sequence AM0722622 as the neotype of the species.

Moreover, concerning the identification of the organisms named after F. leucas (sequences MG437395-96) by Kizildag and Yildiz [25], we should express some doubts. Turkish populations of putative "F. leucas" ([25]: p. 560) significantly differ from the morphological descriptions of the "classical" F. leucas ([3]: pp. 169-170) in several important features (i.e., number of somatic kineties, number and size of the $\mathrm{Mi}$, structure of $\mathrm{CV}$ ) (details in Table 8). Indeed, according to the presented phylogenetic analysis, those organisms belong to the clade of $F$. paramagna [46], and, definitely, the strains described by Kizildag and Yildiz [25] are also more similar to F. paramagna ([46], present study: see Table 8) than to F. leucas morphotype. Actually, the only character that differs between " $F$. leucas" sensu Kizildag and Yildiz [25] and F. paramagna is the Mi (single and big vs. several and small). However, authors do not show in their paper any picture of "F. leucas" Mi, which can only be observed in provided drawings; therefore, it cannot be excluded that they might have overlooked the presence of several relatively small Mi.

As for the other Frontonia spp. studied by Kizildag and Yildiz [25], the ciliate corresponding to the sequence indicated as "Frontonia angusta" (MG456580) in our opinion could have been similarly misidentified: the sequence clusters with F. leucas (AM072622, KY855558), and the ciliate 
Table 8 Comparative morphology of selected freshwater Frontonia species

\begin{tabular}{|c|c|c|c|c|c|c|c|c|}
\hline Characters & $\begin{array}{l}\text { F. leucas sensu } \\
\text { Foissner }\end{array}$ & $\begin{array}{l}\text { F. leucas } \\
\text { Italy, } \\
\text { Neotype }\end{array}$ & $\begin{array}{l}\text { F. leucas } \\
\text { India }\end{array}$ & $\begin{array}{l}\text { F. leucas } \\
\text { Turkey }\end{array}$ & $\begin{array}{l}\text { F. paramagna } \\
\text { China }\end{array}$ & $\begin{array}{l}\text { F. paramagna } \\
\text { India }\end{array}$ & $\begin{array}{l}\text { F. angusta } \\
\text { Neotype }\end{array}$ & $\begin{array}{l}\text { F. angusta } \\
\text { Turkey }\end{array}$ \\
\hline $\begin{array}{l}\text { Average body length } \\
(\mu \mathrm{m})\end{array}$ & 250 & 180 & 173 & 335 & 341 & 293 & 116 & 170 \\
\hline $\begin{array}{l}\text { Cytostome/body } \\
\text { length ratio }\end{array}$ & $1 / 5-1 / 8$ & $1 / 7$ & $1 / 6$ & $1 / 8-1 / 9$ & $1 / 10$ & $1 / 10$ & $1 / 5$ & $1 / 4$ \\
\hline $\begin{array}{l}\text { Somatic kineties, } \\
\text { number }\end{array}$ & 115 & 104 & 100 & 187 & $180-200$ & $166-208$ & 94 & 105 \\
\hline $\begin{array}{l}\text { Peniculi (I, II, III), } \\
\text { number }\end{array}$ & $4-5,4-5,4-5$ & $5,5,5$ & $5,5,5$ & $\begin{array}{l}4-5,4-5,4- \\
5\end{array}$ & $4,4,4$ & $4,4,4$ & $5-4,3,2$ & $4-5,4-5,4-5$ \\
\hline $\begin{array}{l}\text { Vestibular kineties, } \\
\text { number }\end{array}$ & 3 & 3 & 3 & 3 & 3 & 3 & 4 & 3 \\
\hline $\begin{array}{l}\text { Postoral kineties, } \\
\text { number }\end{array}$ & 6 & $5-6$ & 6 & $6-8$ & $6-7$ & $6-7$ & 4 & $4-6$ \\
\hline Micronuclei, number & $2-9$ & $2-3$ & $2-4$ & 1 & $8^{a}$ & $6-14$ & 1 & 1 \\
\hline $\begin{array}{l}\text { Micronuclei, size } \\
(\mu \mathrm{m})\end{array}$ & ND & $3-5$ & $1.5-2$ & $7-8^{\mathrm{a}}$ & ND & $1.5-2.3$ & $7^{\mathrm{a}}$ & $5-8$ \\
\hline CVC, number & $\sim 10$ & $8-11$ & $7-8$ & $10-12$ & $\sim 15$ & $10-14$ & Absent & Absent \\
\hline CVC, structure & Long, twisted & $\begin{array}{l}\text { Long, } \\
\text { twisted }\end{array}$ & $\begin{array}{l}\text { Long, } \\
\text { twisted }\end{array}$ & Branched & Long, straight & Long, straight & Absent & Absent \\
\hline PCV, number & 1 & 1 & 1 & 1 & 1 & $1-3$ & $2-4$ & 1 \\
\hline References & {$[3,4]$} & $\begin{array}{l}\text { Present } \\
\text { study }\end{array}$ & $\begin{array}{l}\text { Present } \\
\text { study }\end{array}$ & {$[25]$} & {$[15,46]$} & Present study & [7] & {$[25]$} \\
\hline
\end{tabular}

CV Contractile vacuole, CVC Canals of contractile vacuole, ND No Data, PCV Pores of contractile vacuole

${ }^{a}$ According to figures

presents a morphology closer to that of our F. leucas from India (population KNP3), rather than F. angusta sensu Foissner et al. [3], which is the paper presenting neotypification. For further details see Table 8.

To summarize, since: i) the sequences presented by Kizildag and Yildiz [25] under the name "Frontonia leucas" (MG437395-6) cluster in the F. paramagna-clade (significantly far from the type sequence of $F$. leucasAM072622); ii) the organisms the sequences (MG437395-6) belonged to are morphologically similar to F. paramagna; and iii) "Frontonia angusta" (MG456580) does not match the morphology of the neotype proposed by Foissner et al. [3], we strongly believe that all those organisms were misidentified. They should be synonymised with $F$. paramagna and F. leucas respectively and renamed accordingly.

\section{Frontonia phylogeny}

Our phylogenetical analysis is in line with the findings of previous studies on Frontonia and Peniculia [9, 11, 1316, 25-28, 47-49]. As a first consideration, the monophyly of Frontonia was not supported by the $18 \mathrm{~S}$ rDNA sequence-based phylogeny $[11,16,26,27,46,50]$. Indeed, Clade 3 included the genus Apofrontonia and resulted to be sister of Paramecium-clade, while Clade 4 resulted to be sister to Marituja-Stokesia-Disematostoma-clade.
Analyzing morphological and ecological data from previous studies (for a review see [50]) some unifying traits for the four retrieved phylogenetic clades of Frontonia can be highlighted.

Clade 1 comprises medium-sized species (body length: $\sim 100-300 \mu \mathrm{m}$ in vivo) from brackish or marine habitats, generally showing a single $\mathrm{CV}$, a number of somatic kineties comprised between 48 and 215, a single Mi (except F. salmastra showing 2-3 Mi), two to four ciliary rows in peniculus III, and a double-rowed PM.

Clade 2 includes medium/large-sized species (body length: 170-600 $\mu \mathrm{m}$ in vivo) from freshwater habitats, generally showing a single CV (except $F$. vesiculosa showing several), a number of somatic kineties comprised between 92 and 208, multiple Mi, four ciliary rows in peniculus III.

Clade 3 comprises small-sized species (body length: $70-150 \mu \mathrm{m}$ in vivo) from brackish habitats, generally showing two CVs (except F. didieri showing only one $\mathrm{CV}$ ), a number of somatic kineties comprised between 61 and 107, a single Mi, two to four ciliary rows in peniculus III.

Clade 4 comprises small-sized species (body length: $60-120 \mu \mathrm{m}$ in vivo) from freshwater and soil (F. terricola) habitats, generally showing one $\mathrm{CV}$, a number of somatic kineties comprised between 40 and 90 , one to two $\mathrm{Mi}$, three ciliary rows in peniculus III. 
It has to be mentioned that the analyzed traits, in some cases, are slightly variable depending on species and can overlap among groups (Clades 1-4), therefore we should be careful to use them as key characters for species identification or clade assignation, without a proper molecular characterization. Indeed, respect to the previous review made by Zhao and colleagues [50], some of such features seem to be rather unreliable, i.e., number of ciliary rows (2-4) in peniculus III for Clade 1 and Clade 3.

As a last consideration, being F. leucas the type species of the genus (herein formally established and neotypified), from a phylogenetic point of view, the "true" Frontonia species should be only those belonging to Clade 1 and Clade 2, which form a monophyletic group comprising the type species of the genus.

Therefore, the "Frontonia" species in Clades 3 and 4, in our opinion, should be attributed to two, or more, newly established genera. Thus, we strongly recommend such a revision for future studies on this topic.

\section{Endosymbionts of Frontonia vernalis and F. paravernalis sp. nov.}

The phylogenetic analysis of Chlorella-clade showed that Chlorella is a not monophyletic genus and phylogenetic relationships are not always resolved, confirming previous study results [51-53]. However, it is evident that endosymbionts of green Frontonia from Russian and Italian populations cluster significantly far away from each other, indicating an independent acquisition, affected by a sort of site-effect. Indeed, from molecular analysis, it came out that the type of green endosymbionts in the studied Frontonia populations differs depending on the site, rather than depending on the species: F. paravernalis from Serchio harbors the almost identical endosymbiont of $F$. vernalis from the same Italian site, but a different one with respect to $F$. paravernalis from St. Petersburg.

Additionally, $P$. chlorelligerum from the same location in St. Petersburg district, manifested very similar cytoplasmic alga phylogenetically close to $M$. planctonica [41]. Thus, it might be the case that, in old Peterhof water body, M. planctonica replaced Chlorella sp. as potential symbiont for different ciliates. Unfortunately, molecular investigation for algal symbionts of $F$. shii was not performed [15], therefore a comparison is unfeasible.

\section{Guideline proposal for an accurate morphological description of Frontonia species}

With the present work, we would like to provide some useful and, in our opinion, substantial guidelines for the proper description of frontoniids based on literature data as well as on our own experience in the field. First of all, concerning the set of features to be considered for species discrimination, we want to stress several points: i) In case of frontoniids, usually, postoral suture is treated as a midventral line running from the oral area to the posterior pole of the ciliate; indeed, there could be a folding (a kind of comb of the cortex), which runs in parallel to a cortex line without kineties. So, the postoral suture is a combination of these two elements (Fig. 3). For instance, the preoral suture is always a line without kineties (Fig. 3). In other words, it is necessary to be precise whenever talking about "suture", remaining strictly adherent to the exact morphological definition of the term. Errors in interpreting the proper morphological meaning of the postoral suture in Frontonia spp. can be found in some recent publications (see [28]: p. 314, Figs $1 \mathrm{~B}, \mathrm{H}$ and, in contrary, $1 \mathrm{~F}$ as well as p. 317, Fig 3D, E; p. 319, Figs 5D, G and in contrary, Fig. 5E, F), where in different figures the same structure is presented either as a cortical comb or as an empty space between left and right parts of ventral side of frontoniid's cell. ii) The characteristics of Mi (size, number, and type) should be considered as required features to be provided for any ciliate description. For Mi type identification see previous study on Paramecium [54]. iii) It is necessary to pay attention to the $\mathrm{CV}$-associated structures: vesicle or canal type, number and structure of canals and PCV, location of CV. Especially for the genus Frontonia, it is important to record shape and interconnection of $\mathrm{CV}$ canals (e.g., are the channels straight, twisted, or forming a network - i.e., creating anostomosis among each other?). In some cases, the collecting canals are not easy to observe; the researcher should very carefully study several cells, not overly squeezing the object. iv) The trichocysts should be described according to their aspect in longitudinal view along with either the shape of their cross-section or their aspect viewed from the top. Indeed, aside from the more common circular cross section found in the extrusomes of the majority of Frontonia species, some trichocysts are more rhombic e.g., in F. salmastra [16], F. marina (Fokin, personal observations). Then, another point to be stressed is to use the important, but sometimes neglected, precaution to avoid providing contradictory data during species description. Unfortunately, it is a quite common error occurring in literature. For example, in a recent publication Cai and colleagues [15] propose a table ([15]: "Table 2", p. 110) to summarise the main morphological characteristics for freshwater and soil frontoniids. Unfortunately, that table presents several inconsistencies: some of them could be treated as technical errors (e.g., the same number indicated body length and somatic kineties for F. leucas and F. atra; instead of number of CVs, the number of PCV is reported as 5-10 for F. vesiculosa), while some others show deeper misleadings (for 
details see: [17]), such as F. pallida [24, 55] and F. elliptica $[18,22]$, indicated as freshwater, instead of brackish water species. Moreover, according to Cai and colleagues [15] a soil species such as $F$. terricola, which lives in highly mineralized solution (in soil) was compared to freshwater species. Since it should be considered much more similar to brackish water species, it might have been avoided a comparison with freshwater ones.

\section{Conclusions}

After a careful and critical revision of literature and according to our research data, we propose to reject $F$. vernalis sensu Ehrenberg $[29,30]$ as a valid description and we provide the neotypification of the species, based on the newly retrieved green frontoniid population from Italy (IPSal+b).

Moreover, in the present study we multidisciplinarly described a novel species of green frontoniid, i.e., $F$. paravernalis sp. nov., and we performed a critical revision of Frontonia phylogeny and literature, with special attention to $F$. vernalis and $F$. leucas. Some issues were fixed and the foundations for future studies that will further improve the state of the art on this genus were laid.

At present, what seems to be solid is that the green Frontonia representatives form a monophyletic clade and that all the more recently described species, i.e., $F$. vernalis (present study), F. paravernalis sp. nov. (present study), and F. shii [15], form a cluster of closely related freshwater ciliates with a single CV and hosting Chlorella-like organisms.

Concerning the critical discussion about the current status of Frontonia systematics, our contribution consisted in providing the $18 \mathrm{~S}$ rDNA sequences of both, F. vernalis (neotype), F. paravernalis sp. nov., and of 14 other frontoniids isolated in different parts of the world over a research period of 15 years. Among them, at least two resulted new species (populations $\mathrm{VmFr} / \mathrm{IPSal}$ - and BJ4), and four of them were already known frontoniids ( $F$. atra, F. fusca, F. minuta, and $F$. vesiculosa) for which the gene sequence was obtained for the very first time.

The last contribution of our work dealt with the neotypification of $F$. leucas through the deposition of the neotype material in a museum collection, and the formal establishment of $F$. leucas as type species of the genus which was heretofore lacking. Filling this gap, in our view, was definitely crucial in order to properly plan further studies on Frontonia and the revision of its systematics.

\section{Methods}

\section{Sampling sites and conditions}

Green Frontonia spp. were repeatedly sampled in Italy between May 2016 and June 2018 (in details: May and
November 2016, February and March of 2017, June 2018) in the permanent freshwater shallow small pond located along the Ligurian sea coastline close to the mouth of Serchio River (Parco Naturale di Migliarino San Rossore Massaciuccoli, Migliarino, Pisa district, Tuscany, Italy; N. $43^{\circ} 47^{\prime} 7.524^{\prime \prime}$ E. $10^{\circ} 15^{\prime} 57.44^{\prime \prime}$ ): populations IPSal $+\mathrm{sm}$, IPSal+b (Table 1). Water temperature in sampling site ranged between 14 and $25^{\circ} \mathrm{C}$; pH was $7.6-$ 7.8.

The Russian populations of green Frontonia spp. were collected in the period 2014-2017 during all seasons in Old Peterhof, in the small, but relatively deep permanent ditch in the corner of the English park: Peterhof, St. Pe-

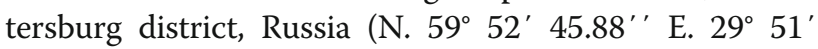
37.224' '): populations FSPBsm, FSPBb (Table 1). Water temperature in sampling site ranged from $1{ }^{\circ} \mathrm{C}$ (January) up to $22^{\circ} \mathrm{C}$ (August). The $\mathrm{pH}$ was 6.6-7.1.

Two different kinds of green Frontonia spp. were observed in both the samplings (i.e., in Italy and in Russia) based on the cell size: the "small" cell (IPSal+sm, FSPBsm) and the "big" cell (IPSal+b, FSPBb) populations. After a deep investigation, two different species were recognized and decribed: F. paravernalis sp. nov. (IPSal+sm, FSPBsm) and F. vernalis. (IPSal+b). The "big" cell population $\mathrm{FSPBb}$ was identified as $F$. vernalis on morphological base; due to the lack of molecular data on this population, it is not possible to assign it with certainty (see Results).

Additional Frontonia spp. were collected during our sampling activity carried out from 2005 to 2017 in Italy (Tuscany, Sardinia) and in India (Andhra Pradesh), as listed in Table 1. Some of the retrieved populations were maintained as polyclonal cultures for some time in the laboratory. Several of them, were recognised as $F$. atra, $F$. minuta, $F$. vesiculosa, $F$. paramagna, F. leucas, and $F$. fusca [10], described according to morphological and molecular criteria, and herein used for phylogenetic reconstruction of the genus Frontonia. In the case of $F$. fusca, the article with the redescription of the ciliate was published already a decade ago [10].

\section{Living cultures}

Unfortunately, we did not succeed to establish monoclonal cultures of green frontoniids, but they could be kept in laboratory for some weeks/months (depending on the population) by feeding them with Phaeodactylum tricornutum (diatom, monoclonal culture) and Peridinium sp. (dinoflagellate, native isolate), in the original Falcon tube $(50 \mathrm{ml})$ used for sampling. Specimens of green Frontonia spp. collected by micropipette could survive inside $3 \mathrm{ml}$-depression slides for some weeks, without feeding, but with day-time illumination. 


\section{Live observations}

Ciliates were observed using differential interference contrast (DIC) microscopy with a Leitz (Germany) microscope at a magnification of $\times 300-1250$ with the help of a compression device [56]. Ciliates were photographed using a digital camera (Canon Power Shot S45) and True Chrome HDII Screen. Morphometric measurements were made both in vivo and after staining (i.e., after Feulgen staining and silver impregnation).

For the examination of swimming behaviour, ciliates were observed in a glass $3 \mathrm{ml}$-depression slide under a dissection microscope Wild M3 (Switzerland) at a magnification of $\times 12.5-50$. Photoreactivity of ciliates was roughly checked in small Petri dishes, half decorated by dark case and illuminated by natural or artificial light.

\section{Fixation, staining and fluorescence in situ hybridization}

Investigated ciliates were fixed with Champy's solution and silver nitrate stained after Corliss [57]. Feulgen staining procedure after fixation in Bouin's fluid or in a mixture of $95 \%$ alcohol with $1 \%$ solution of celoidin in diethyl ether (our own recipe) was used to reveal the nuclear apparatus. In order to check the possibility that the Feulgen-positive particles observed in the cytoplasm of IPSal+sm population were symbiotic bacteria, ciliates were processed for Fluorescence In Situ Hybridization (FISH) using the Eubacterial probe EUB338I [58] and the Alphaprotobacterial probes Alf1b [59]. Fixed cells were observed under UV-light with fluorescent microscope Leica DMR (Germany).

\section{Transmission electron microscopy (TEM)}

TEM was used to investigate the nuclear apparatus, possible intracellular symbionts aside of algae and other cytoplasmatic structures in F. paravernalis sp. nov.. Cells were processed through a routinely used protocol [60].

\section{DNA extraction}

The Frontonia cells were washed several times in glass depression slides with sterile distilled water before being fixed in $70 \%$ ethanol. Total genomic DNA was extracted from 40 (IPSal+sm), 30 (IPSal+b) and 20 (IPSal-) cells using the NucleoSpinTM Plant II kit (Macherey-Nagel, Germany).

\section{Whole genome amplification}

The single cell whole genome amplification was performed on green Frontonia populations with symbiotic associations with Chlorella-like alga (IPSal+sm and IPSal+b from Italy; FSPBsm and FSPBb from Russia), using REPLI-g kit (Qiagen, Hilden, Germany). Cells were prepared with a series of six washing steps in distilled water inside glass depressions using glass micropipette, and finally cells were transferred to
PBS. Then, a single cell of Frontonia plus $4 \mu \mathrm{L}$ of PBS was withdrawn from the depressions and transferred to PCR microtubes. Next steps were performed according to manufacturer instruction. A microtube with only PBS and reagents from the kit was used as negative control.

\section{S rDNA amplification and sequencing}

Polymerase chain reactions (PCR) on the $18 \mathrm{~S}$ rDNA gene, were performed with a C1000TM Thermal Cycler (Bio-Rad, Hercules, CA) employing TaKaRa PCR reagents and Ex Taq (Takara Bio Inc., Japan). All PCRs were performed in a $40 \mu \mathrm{l}$ reaction volume following the manufacturer's instructions.

The amplification of $18 \mathrm{~S}$ rDNA sequences from IPSal+ $\mathrm{sm}$, IPSal+b, and IPSal- populations was performed using DNA material from total genomic extraction, while amplification for FSPBsm and FSPBb populations was performed starting from DNA material obtained from WGA.

For PCR on IPSal+sm and IPSal+b we employed the forward primer $18 \mathrm{~S}$ F9 (5'- CTG GTT GAT CCT GCC AG -3') [61] and the reverse primer $18 \mathrm{~S}$ R1513 Hypo (5'TGA TCC TTC YGC AGG TTC $\left.-3^{\prime}\right)[62,63]$ with the following settings: $180 "$ at $94{ }^{\circ} \mathrm{C}$, followed by a series of 35 identical amplification cycles (denaturation at $94{ }^{\circ} \mathrm{C}$ for $30^{\prime \prime}$, annealing at $55^{\circ} \mathrm{C}$ for $30^{\prime \prime}$, extension at $72^{\circ} \mathrm{C}$ for $\left.120^{\prime \prime}\right)$. The amplification of IPSal- was done on a diluted extraction product using forward primer 18S F9 Euk and reverse primer R1513 Hypo with the following settings: $180^{\prime \prime}$ at $94^{\circ} \mathrm{C}$, followed by a series of 45 identical amplification cycles (denaturation at $94{ }^{\circ} \mathrm{C}$ for $30^{\prime \prime}$, annealing at $55^{\circ} \mathrm{C}$ for $30^{\prime \prime}$, extension at $72^{\circ} \mathrm{C}$ for $\left.120^{\prime \prime}\right)$. A seminested PCR was performed on the PCR product for IPSal- using forward primer 18S F9 and Penic R1280 (5' - CGA CAC GTC CTA ACA AGA-3') for the first reaction and using forward primer Penic F82 (5'-GAA ACT GCG AAT GGC TC$\left.3^{\prime}\right)$ and reverse primer $18 \mathrm{~S}$ R1513 Hypo for the second reaction. The amplification of the samples was obtained using the following settings: $30 "$ at $94{ }^{\circ} \mathrm{C}$ followed by a series of 40 identical cycles (denaturation at $94^{\circ} \mathrm{C}$ for $30^{\prime \prime}$, annealing at $48^{\circ} \mathrm{C}$ for $30^{\prime \prime}$, extension at $72{ }^{\circ} \mathrm{C}$ for $\left.120^{\prime \prime}\right)$.

To obtain the 18S rDNA sequence from FSPBsm and FSPBb populations we performed a seminested PCR starting from the WGA product with primers 18S F9/ Penic R1280 and Penic F82/18S R1513 Hypo, as described for IPSal- population. PCR products were purified using EuroGOLD Cycle-Pure Kit (EuroClone, Milan, Italy) and sent to GATC Biotech Company (Germany) where the samplese were sequenced using three internal primers. 


\section{Frontonia 185 rDNA sequencing}

For populations IPSal+sm and IPSal+b we employed the following sequencing primers: 18S R536 (5'-CTG GAA TTA CCG CGG CTG-3'), 18S R1052 (5'-AAC TAA GAA CGG CCA TGC A-3'), and 18S F783 (5'-GAC GAT CAG ATA CCG TC-3') [64].

For IPSal- population we employed Penic R661 (5'ACT AAT GCC CCC ATC TGT-3'), Penic R1280, and Penic F987 (5'-GGT CAA AAC ATG GAT GGG A-3') as sequencing primers.

For populations FSPBsm and FSPBb we used $18 \mathrm{~S}$ Penic R661, 18S R1052, and 18S F783 as sequencing primers. Unfortunately, we did not get suitable results for Frontonia FSPBb from Russia.

As for the other Frontonia in analysis (Table 1), they were processed for $18 \mathrm{~S}$ rDNA amplification and sequencing according to Serra et al. [65].

\section{Endosymbiont $18 \mathrm{~S}$ rDNA sequencing}

For the sequencing of the $18 \mathrm{~S}$ rDNA of FSPBsm F. paravernalis' endosymbionts we employed the primers $18 \mathrm{~S}$ R536 and 18S R1052, and we designed the speciesspecific primer F838_Meyer (5'- GGA TGT TTC TTC GAT GAC TC-3').

We faced several problems in sequencing the $18 \mathrm{~S}$ rDNA segment of endosymbionts from populations IPSal+sm and IPSal+b using Sanger sequencing. Therefore, the DNA material obtained from WGA was processed with a Nextera XT library and sequenced at Admera Health (South Plainfield, USA), using Illumina HiSeq $X$ technology to generate $75,709,674$ and 74,962 , 776 reads (paired-ends $2 \times 150$ bp) for IPSal+sm and IPSal+b populations, respectively. Preliminary assembly of resulting reads from both the organisms was performed using SPAdes software ( $\mathrm{v}$ 3.6.0) [66]. The complete $18 \mathrm{~S}$ rDNA sequence belonging to the endosymbiotic Chlorella-like organisms, was computationally predicted from the assembled sequences using Barrnap [67], and manually verified via BLAST analysis.

\section{Phylogenetic analyses}

The 18S rDNA of the studied Frontonia spp. and the algal symbionts were aligned with the automatic aligner of the ARB software package version 5.5 [68] on the SSU ref. NR102 SILVA database [69].

For the analysis of frontoniids, 71 sequences of other Oligohymenophoreans, 62 of which belonging to the subclass Peniculia (ingroup), were selected (dataset 1).

For the analysis on the symbionts, 46 sequences of other members of Chlorella-clade were selected, plus 7 other sequences belonging to Parachlorella-clade [51] as outgroup (dataset 2).

After manual editing to optimize base pairing in the predicted rRNA stem regions in each dataset, the two alignments were trimmed at both ends up to the length of the shortest sequence. A positional filter was applied to dataset 2 , to keep only those columns where the most conserved base was present in at least 5\% of the sequences. Resulting matrices contained respectively 1615 (dataset 1) and 1839 (dataset 2) nucleotide columns, which were used for phylogeny and for the identity matrix calculation.

For each phylogenetic dataset, the optimal substitution model was selected with jModelTest 2.1 [70] according to the Akaike Information Criterion. Maximum likelihood (ML) trees were calculated with the PHYML software version 2.4 [71] from the ARB package, performing 100 pseudo-replicates. Bayesian inference (BI) trees were inferred with MrBayes 3.2 [72], using three runs each with one cold and three heated Monte Carlo Markov chains, with a burn-in of $25 \%$, iterating for $1,000,000$ generations.

\section{Abbreviations}

BI: Bayesian inference; CV: Contractile vacuole; FISH: Fluorescence in situ hybridization; Ma: Macronucleus; Mi: Micronucleus; ML: Maximum likelihood; PCR: Polymerase chain reactions; PCV: Pore of contractile vacuole; PK: Postoral kineties; PM: Paroral membrane; VK: Vestibular kineties

\section{Supplementary Information}

The online version contains supplementary material available at https://doi. org/10.1186/s40850-021-00067-9.

Additional file 1: Supplementary Figure 1. Morphology of Frontonia paravernalis sp. nov. (Russian population - FSPBsm). a) Feulgen stained cell, showing nuclear apparatus: macronucleus (Ma) and micronuclei (Mi); b) ventral side of a silver stained specimen, showing oral and somatic ciliature. Chlorella-like endosymbionts (Ch) are visible behind the cortex as well; c) detail of oral aperture (OA). OA - oral aperture; P1, P2, P3 - first, second, third peniculus; PCV - pore of contractile vacuole; PK - postoral kineties; PM - paroral membrane; PtS - postoral suture; VK - vestibular kineties. Bars stand for $20 \mu \mathrm{m}$.

Additional file 2: Supplementary Figure 2. Morphology of Frontonia leucas (Italian population - IPBG). a) Living cell showing oral aperture $(\mathrm{OA})$ and macronucleus (Ma) position; b) living cell showing trichocysts (Tc) under the cell cortex and contractile vacuole (CV) with its collecting canals (CC); c) detail of $\mathrm{Ma}$ and three micronuclei (Mi) in a living cell; d) Feulgen stained cell, showing nuclear apparatus: Ma and three Mi; e), f) ventral and dorsal somatic ciliature of a silver stained specimen; g) silver stained dividing cell; h) closer view of F. leucas oral ciliature after silver staining. CC - collecting canals; CV - contractile vacuole; Ma macronucleus; Mi - micronucleus; OA - oral aperture; P1, P2, P3 - first, second, third peniculus; PCV - pore of contractile vacuole; PK - postoral kineties; PM - paroral membrane; PrS - preoral suture; PtS - postoral suture; Tc - trichocysts; VK - vestibular kineties; Arrow - dorsal set of kineties parallel to the preoral suture; Double Arrowhead - longitudinal dorsal stripe of adjacent kineties. Bars stand for $20 \mu \mathrm{m}$ (a, b, e-h), $10 \mu \mathrm{m}$ (c, d).

\section{Acknowledgements}

The authors are grateful to the Marine Biology Laboratory, Andhra University, India, for providing the research facilities. In particular, Professor Chaganti Kalavati, Professor Raman Akkur, Professor Bhagavatula Sandeep, and Professor Prabhakara Rao Yallapragada are acknowledged for their valuable aid. Dr. Ilaria Andreoli, Dr. Charan Kumar Basuri, and Dr. Adireddy Sathiaveny are acknowledged for providing Frontonia population data and molecular sequences. Ms. Natalia Lebedeva (Centre of Core Facilities "Culture 
Collections of Microorganisms", Research Park, Saint Petersburg State University, Saint Petersburg, Russia) is acknowledged for sampling support in Russia. Special acknowledgements to Mr. Simone Gabrielli for tree and photo-editing support.

\section{Nomenclature acts}

The present work has been registered in ZooBank (code: urn:Isid:zoobank.org:pub: F92DB5E1-19B1-4FB3-A2D4-AEDA4529DAD2), as well as the new Frontonia species: Frontonia paravernalis (code: urn:Isid:zoobank.org:act:10B01A7E-A4A7-45F0-B66B-7E6180AEC9F7). The correspondent web pages are available at the following addresses: http://www.zoobank.org/ References/F92DB5E1-19B1-4FB3-A2D4-AEDA4529DAD2, http://www. zoobank.org/NomenclaturalActs/10b01a7e-a4a7-45f0-b66b-7e6180aec9f7.

\section{Authors' contributions}

Conceptualization: SIF, GP, VS. Sampling and culturing: SIF, VS, VN Morphological and ultrastructural analyses: SIF, ADA, VN. Molecular analyses: VS, ADA, VN, LG. Bioinformatics: LG, GP. Phylogeny analyses: VS, GP. Visualization: SIF, VS, ADA, LM, GP. Funding acquisition: GP, SIF, VS. Work supervision: SIF, GP, LM. Writing - original draft: VS, SIF. Writing - review \& editing: GP, LM. All authors have read and approved the manuscript.

\section{Funding}

This work was supported by the European Commission FP7-PEOPLE-2009IRSES project CINAR PATHOBACTER (247658) (for sampling travel and researchers' exchanges), the University of Pisa PRA_2018_63 (for article conceptualization). The research leading to these results has received funding from the European Community's H2020 Programme H2020-MSCA-RISE 2019 under grant agreement $n^{\circ}$ 872767), (researchers' support during the analysis and the writing phases). The present study was supported by the Fondazione Cassa di Risparmio di Pistoia e Pescia - giovani@ricercascientifica2019 fellowship ( $n^{\circ}$ 2019.0380) (researchers' support during the analysis and the writing phases).

\section{Availability of data and materials}

II data generated or analysed during this study are included in this published article. 185 rDNA sequences have been deposited in GenBank and accession numbers are showed in the Results section, in Table 1, in Figs. 6 and 7 of the present manuscript. Permanent slides are available from the corresponding author on reasonable request.

\section{Declarations}

\section{Ethics approval and consent to participate}

Not applicable.

\section{Consent for publication}

Not applicable.

\section{Competing interests}

The authors declare that they have no competing interests.

\section{Author details}

${ }^{1}$ Department of Biology, University of Pisa, Pisa, Italy. ${ }^{2}$ School of Biosciences and Veterinary Medicine, University of Camerino, Camerino, Italy. ${ }^{3} \mathrm{CIME}$, Centro Interdipartimentale di Microscopia Elettronica, Università di Pisa, Pisa, Italy. ${ }^{4}$ CISUP, Centro per I'Integrazione della Strumentazione dell'Università di Pisa, Pisa, Italy. ${ }^{5}$ Department of Invertebrate Zoology, St. Petersburg State University, St. Petersburg, Russia. ${ }^{6}$ St. Petersburg Branch of the S.I. Vavilov Institute of History of Science and Technology Russian Academy of Sciences, St. Petersburg, Russia.

\section{Received: 28 May 2020 Accepted: 19 February 2021} Published online: 08 March 2021

\section{References}

1. Corliss JO. The ciliated protozoa. Characterization, classification, and guide to the literature. 2nd ed. Oxford: Pergamon Press; 1979.

2. Puytorac P, Grain J, Mignot J-P. Précis de Protistologie. Soc. Nouv. Ed. Paris: Boubée; 1987
3. Foissner W, Berger H, Kohmann F. Taxonomische und okologische Revision der Ciliaten des Saprobiensystems. Band III: Hymenostomata, Prostomatida, Nassulida. — Informationsberichte des Bayer. Landesamtes für Wasserwirtschaft. 1994;5/92:1-502.

4. Foissner $\mathrm{W}$, Berger $\mathrm{H}$, Schaumburg J. Identification and ecology of limnetic plankton ciliates. Bavarian State Office for Water Management. Rep Issue. 1999;3/99:1-793.

5. Lynn DH, Small EB. Phylum Ciliophora. In: Lee JJ, Hutner SH, Bovee EC, editors. An illustrated guide to the Protozoa. 2nd ed. Lawrence: Allen Press; 2000. p. 371-655.

6. Strüder-Kypke MC, Wright A-DG, Fokin SI, Lynn DH. Phylogenetic relationships of the subclass Peniculia (Oligohymenophorea, Ciliophora) inferred from small subunit rRNA gene sequences. J Eukaryot Microbiol. 2000;47:419-29.

7. Foissner W, Agatha S, Berger H. Soil ciliates (Protozoa, Ciliaphora) from Namibia (Southwest Africa) with emphasis on two contrasting environments, the Etosha region and the Namib desert. Denisia. 2002;5:11459

8. Fokin SI, Przyboś E, Chivilev SM, Beier CL, Horn M, Skotarczak D, Wodecka B, Fujishima M. Morphological and molecular investigations of Paramecium schewiakoffi sp. nov. (Ciliophora, Oligohymenophorea) and current status of paramecia distribution and taxonomy. Eur J Protistol. 2004;40:225-43.

9. Fokin SI, Andreoli I, Verni F, Petroni G. Apofrontonia dohrni sp. n. and the phylogenetic relationships within Peniculia (Protista, Ciliophora, Oligohymenophorea). Zool Scr. 2006;35:289-300.

10. Fokin SI. Rediscovery and characterisation of Frontonia fusca (Quennerstedt, 1869) Kahl, 1931 (Ciliophora, Peniculia). Denisia. 2008;23:251-9.

11. Gao S, Chen Z, Shao C, Long H, Al-Rasheid KAS, Song W. Reconsideration of the phylogenetic position of Frontonia-related Peniculia (Ciliophora, Protozoa) inferred from the small subunit ribosomal RNA gene sequences. Acta Protozool. 2008;47:47-54.

12. Long H, Song W, Al-Rasheid KAS, Wang Y, Yi Z, Al-Quraishy SA, Lin X, AlFarraj S. Taxonomic studies on three marine species of Frontonia from northern China: F. didieri n. sp., F. multinucleata n. sp. and F. tchibisovae Burkovsky, 1970 (Ciliophora: Peniculida). Zootaxa. 2008;1687:35-50.

13. Pan X, Gao F, Liu W, Fan X, Warren A, Song W. Morphology and SSU rRNA gene sequences of three Frontonia species, including a description of $F$. subtropica spec. nov. (Ciliophora, Peniculida). Eur J Protistol. 2013a;49:67-77.

14. Pan X, Liu W, Yi Z, Fan X, Al-Rashid KAS, Lin X. Studies on three diverse Frontonia species (Ciliophora, Peniculida), with brif notes on 14 marine or brackish congeners. Acta Protozool. 2013b;52:35-49.

15. Cai X, Wang C, Pan X, El-Serehy HA, Mu W, Gao F, Qiu Z. Morphology and systematics of two freshwater Frontonia species (Ciliophora, Peniculida) from northeastern China, with comparisons among the freshwater Frontonia spp. Eur J Protistol. 2018:63:105-16.

16. Fokin SI, Serra V, Ferrantini F, Modeo L, Petroni G. "Candidatus Hafkinia simulans" gen. nov., sp. nov., a novel Holospora-like bacterium from the macronucleus of the rare brackish water ciliate Frontonia salmastra (Oligohymenophorea, Ciliophora): multidisciplinary characterization of the new endosymbiont and its host. Microb Ecol. 2019;77:1092-106.

17. Fokin SI. On the importance of attentive reading of research articles: the case study of Frontonia (Peniculia, Oligohymenophora, Ciliophora) species descriptions and redescriptions. Protistology. 2019;13:36-41. https://doi. org/10.21685/1680-0826-2019-13-1-5.

18. Kahl A. Holotricha. In: Dahl F. edd. Die Tierwelt Deutschlands and der angrenzenden Meeresteile. 21 Teil. Urtiere oder Protozoa. G. Fisher, Jena. S. 1931:181-398.

19. Kahl A. Infusorien. Handbücher für die praktische wissenschaftliche Arbeit 31/32, 1943. 1-52 pp. (Reprinted in Acta Protozool. 2004;43(Suppl.):11-62).

20. Dragesco J. Frontoniidae In: Ciliés libres du Cameroun. Annls Fac Sci Univ Fed Cameroun. 1970;9:47-57.

21. Roque M, Puytorac P. Frontonia canadensis sp. nov. (Cilié Hyménostome Péniculien). Naturaliste Can. 1972;99:411-6.

22. Dragesco J, Dragesco-Kernéis A. Cilies libres de l'Afrique intertropicale. Faune Tropicale. 1986;26:1-559.

23. Dragesco J, Dragesco-Kernéis A. Ciliates from Lake Tanganyika. Eur J Protistol. 1991;26:222-4.

24. Carey PG. Marine interstitial ciliates. An illustrated key. London, New York: Chapman \& Hall; 1992

25. Kizildag S, Yildiz I. Morphology and molecular phylogeny of four Frontonia species from Turkey (Protista, Ciliophora). Zootaxa. 2019;4609:548-64. 
26. Andreoli I, Fokin SI, Verni F, Petroni G. Phylogenetic relationships within frontoniids. J Eukaryot Microbiol. 2007a;54:28S Abstract 72A

27. Andreoli I, Fokin SI, Verni F, Petroni G. Phylogenetic relationships within peniculine ciliates and the paraphyly of Frontonia. Protistology. 2007b;5:12 Abstract.

28. Fan X, Lin X, Liu W, Xu Y, Al-Farra SA, Al-Rasheid KAS, Warren A. Morphology of three new marine Frontonia species (Ciliophora; Peniculida) with note on the phylogeny of this genus. Eur J Protistol. 2013;49:312-23.

29. Ehrenberg CG. Dritter Beitrag zur Erkenntniss grosser Organisation in der Richtung des kleinsten Raumes. Berlin: Abhandlungen der Preussischen Akademie der Wissenschaften (Berlin) ausden Jahre; 1833.

30. Ehrenberg CG. Die Infusionsthierchen als vollkommene Organismen. Ein Blick in das tiefere organische Leben de Natur. Verlag von Leopold Voss (ed), Leipzig; 1838. 1-xvii, 1-548, pls. 1-64.

31. Bullington WE. A study of spiraling in the ciliate Frontonia with a review of the genus and description of two new species. Arch Protistenkd. 1939;92: 10-66.

32. Quennerstedt A. Bidrag till Sveriges Infusorie-fauna III. Acta Universitatis Lundensis. 1869;6:1-35.

33. Berninger UG, Finlay BJ, Canter HM. The spatial distribution and ecology of zoochlorellae-bearing ciliate in a productive pond. J Protozool. 1986;33:557-63.

34. Finlay BJ, Berninger UG, Stewart $\sqcup$, Hindle RM, Davidson W. Some factors controlling the distribution of two pond-dwelling ciliates with algal symbionts (Frontonia vernalis and Euplotes daidaleos). J Protozool. 1987;34: 349-56.

35. Esteban GF, Fenchel T, Finlay BJ. Mixotrophy in ciliates. Protist. 2010;161: $621-41$

36. Warren A, Patterson DJ, Dunthorn M, Clamp JC, Achilles-Day UE, Aescht E, Al-Farraj SA, Al-Quraishy S, Al-Rasheid KAS, Carr M, Day JG, Dellinger M, El-Serehy HA, Fan Y, Gao F, Gao S, Gong J, Gupta R, Hu X, Kamra K, Langlois G, Lin X, Lipscomb D, Lobban CS, Luporini P, Lynn DH, Ma H, Macek M, Mackenzie-Dodds J, Makhija S, Mansergh RI, Martín-Cereceda M, McMiller N, Montagnes DJS, Nikolaeva S, Ong'ondo GO, Pérez-Uz B, Purushothaman J, Quintela-Alonso P, Rotterová J, Santoferrara L, Shao C, Shen Z, Shi X, Song W, Stoeck T, La Terza A, Vallesi A, Wang M, Weisse T, Wiackowski K, Wu L, Xu K, Yi Z, Zufall R, Agatha S. Beyond the 'Code': a guide to the description and documentation of biodiversity in ciliated protists (Alveolata, Ciliophora). J Eukaryot Microbiol. 2017:64:539-54.

37. Serra V, Gammuto L, Nitla V, Castelli M, Lanzoni O, Sassera D, Bandi C, Sandeep BV, Verni F, Modeo L, Petroni G. Morphology, ultrastructure, genomics, and phylogeny of Euplotes vanleeuwenhoeki sp. nov. and its ultrareduced endosymbiont "Candidatus Pinguicoccus supinus" sp. nov. Sci Rep. 2020;10:1-27. https://doi.org/10.1038/s41598-020-76348-z.

38. Schewiakoff W. Beitrage zur Kenntniss der Holotrichen Ciliaten. Biblioteca Zoologica. Cassel, Verlag von Theodor Fischer. 1889.

39. Schewiakoff WT. Organization and systematics of Infusoria Aspirotricha (Holotricha auctorum). Mem Imp Acad Sci SPb Ser. 1896;VIII:4 (in Russian).

40. Fokin SI, Schweikert M. Bacterial endobionts of Frontonia leucas (Ciliophora, Peniculida). Eur J Protistol. 2003:39:311-8.

41. Lanzoni O, Fokin SI, Lebedeva N, Migunova A, Petroni G, Potekhin A. Rare freshwater ciliate Paramecium chlorelligerum Kahl, 1935 and its macronuclear symbiont "Ca. Holospora parva". PLoS One. 2016;11:e0167928. https://doi. org/10.1371/journal.pone.0167928.

42. Rosati G, Modeo L. Extrusomes in ciliates: diversification, distribution, and phylogenetic implications. J Eukaryot Microbiol. 2003;50:383-402. https:// doi.org/10.1111/j.1550-7408.2003.tb00260.x.

43. Dujardin MF. Histore naturelle des zoophytes. Infusoires. Paris: Libraire encyclopedique de Roret; 1841.

44. Arroyo J, Perez-Silva J. Morphology of Frontonia betica Arroyo \& Pérez-Silva 1977 (Ciliophora, Peniculida). Eur J Protistol. 1994;30:342-6.

45. Aescht E. Catalogue of the generic names of ciliates (Protozoa, Ciliophora). Denisia. 2001;1:1-350.

46. Chen Y, Zhao Y, Pan X, Ding W, Al-Rasheid KAS, Qiu Z. Morphology and phylogeny of a new Frontonia ciliate, F. paramagna spec. nov. (Ciliophora, Peniculida) from Harbin, Northeast China. Zootaxa. 2014; 3827:375-86.

47. Fan X, Chen X, Song W, Al-Rasheid KAS, Warren A. Two novel marine Frontonia species, Frontonia mengi spec. nov. and Frontonia magna spec. nov. (Protozoa; Ciliophora), with notes on their phylogeny based on small-subunit rRNA gene sequence data. Int J Syst Evol Microb. 2011:61:1476-86.

48. Xu Y, Gao F, Fan X. Reconsideration of the systematics of Peniculida (Protista, Ciliophora) based on SSU rRNA gene sequences and new morphological features of Marituja and Disematostoma. Hydrobiologia. 2018;806:313-31.

49. Serra V, Fokin SI, Gammuto L, Nitla V, Castelli M, Basuri CK, Satyaveni A, Sandeep BV, Letizia Modeo L, Petroni G. Phylogeny of Neobursaridium reshapes the systematics of Paramecium (Oligohymenophorea, Ciliophora). Zool Scr. 2020:1-28. https://doi.org/10.1111/zsc.12464.

50. Zhao Y, Yi Z, Gentekaki E, Zhan A, Al-Farraj SA, Song W. Utility of combining morphological characters, nuclear and mitochondrial genes: an attempt to resolve the conflicts of species identification for ciliated protists. Mol Phylogen Evol. 2016;94:718-29.

51. Krienitz L, Hegewald EH, Hepperle D, Huss VA, Rohr T, Wolf M. Phylogenetic relationship of Chlorella and Parachlorella gen. nov. (Chlorophyta, Trebouxiophyceae). Phycologia. 2004;43:529-42.

52. Hoshina R, Iwataki M, Imamura N. Chlorella variabilis and Micractinium reisseri sp. nov. (Chlorellaceae, Trebouxiophyceae): Redescription of the endosymbiotic green algae of Paramecium bursaria (Peniculia, Oligohymenophorea) in the 120th year. Phycol Res. 2010;58:188-201.

53. Kawaida H, Ohba K, Koutake Y, Shimizu H, Tachida H, Kobayakawa Y. Symbiosis between hydra and chlorella: molecular phylogenetic analysis and experimental study provide insight into its origin and evolution. Mol Phylogenet Evol. 2013;66:906-14.

54. Fokin SI. Morphological diversity of the micronuclei in Paramecium. Arch Protistenkd. 1997;148:375-87.

55. Czapik A. Frontonia pallida sp. n.: un nouveau cilié psammophile (Hymenostomata, Peniculina). Acta Protozool. 1979;18:527-30.

56. Skovorodkin IN. A device for immobilization of biological objects in light microscope studies. Cytology (Saint-Petersburg). 1990;32:301-2 (in Russian with English summary).

57. Corliss JO. Silver impregnation of ciliated protozoa by the Chatton-Lwoff technique. Stain Technol. 1953;28:97-100.

58. Amann RI, Binder BJ, Olson RJ, Chisholm SW, Devereux R, Stahl DA. Combination of $16 \mathrm{~S}$ rRNA-targeted oligonucleotide probes with flow cytometry for analyzing mixed microbial populations. Appl Environ Microbiol. 1990:56:1919-25.

59. Manz W, Amann R, Ludwig W, Wagner M, Schleifer KH. Phylogenetic oligodeoxynucleotide probes for the major subclasses of proteobacteria: problems and solutions. Syst Appl Microbiol. 1992;15:593-600.

60. Fokin SI, Görtz HD. Caedibacter macronucleorum sp. nov., a bacterium inhabiting the macronucleus of Paramecium duboscqui. Arch Protistenkd. 1993;143:319-24.

61. Medlin L, Elwood HJ, Stickel S, Sogin ML. The characterization of enzymatically amplified eukaryotic 16S-like rRNA-coding regions. Gene. 1988;71:491-9.

62. Petroni G, Dini F, Verni F, Rosati G. A molecular approach to the tangled intrageneric relationships underlying phylogeny in Euplotes (Ciliophora, Spirotrichea). Mol Phylogenet Evol. 2002;22:118-30.

63. Nitla V, Serra V, Fokin SI, Modeo L, Verni F, Sandeep BV, Kalavati C, Petroni G. Critical revision of the family Plagiopylidae (Ciliophora: Plagiopylea), including the description of two novel species, Plagiopyla ramani and Plagiopyla narasimhamurtii, and redescription of Plagiopyla nasuta Stein, 1860 from India. Zool J Linnean Soc. 2019;186:1-45. https://doi.org/10.1093/ zoolinnean/zly041.

64. Rosati G, Modeo L, Melai M, Petroni G, Verni F. A multidisciplinary approach to describe Protists: a morphological, ultrastructural, and molecular study on Peritromus kahli (Ciliophora, Heterotrichea). J Eukaryot Microbiol. 2004;51:49-59.

65. Serra V, Fokin SI, Castelli M, Basuri CK, Nitla V, Verni F, Sandeep BV, Kalavati C, Petroni G. "Candidatus Gortzia shahrazadis", a novel endosymbiont of Paramecium multimicronucleatum and a revision of the biogeographical distribution of Holospora-like bacteria. Front Microbiol. 2016;7:1704. https:// doi.org/10.3389/fmicb.2016.01704.

66. Bankevich A, Nurk S, Antipov D, Gurevich AA, Dvorkin M, Kulikov AS, Lesin VM, Nikolenko SI, Pham S, Prjibelski AD, Pyshkin AV, Sirotkin AV, Vyahhi N, Tesler G, Alekseyev MA, Pevzner PA. SPAdes: a new genome assembly algorithm and its applications to single-cell sequencing. J Bioinforma Comput Biol. 2012;19:455-77. https://doi.org/10.1089/cmb.2012.0021.

67. Seemann T. barrnap 0.5: rapid ribosomal RNA prediction. 2013. http://www. vicbioinformatics.com/ 
68. Westram R, Bader K, Pruesse E, Kumar Y, Meier H, Glöckner FO, Ludwig W. ARB: a software environment for sequence data. In: de Bruijn FJ, editor. Handbook of molecular microbial ecology I: metagenomics and complementary approaches: Wiley-Blackwell Publishing; 2011. p. 399-406. https://doi.org/10.1002/9781118010518.ch46.

69. Quast C, Pruesse E, Yilmaz P, Gerken J, Schweer T, Yarza P, Peplies J, Glöckner FO. The SILVA ribosomal RNA gene database project: improved data processing and web-based tools. Nucl Acids Res. 2013;41:D590-6. https://doi.org/10.1093/nar/gks1219.

70. Darriba D, Taboada GL, Doallo R, Posada D. jModelTest 2: more models, new heuristics and parallel computing. Nat Methods. 2012;9:772. https://doi. org/10.1038/nmeth.2109.

71. Guindon S, Gascuel O. A simple, fast, and accurate algorithm to estimate large phylogenies by maximum likelihood. Syst Biol. 2003;52:696-704. https://doi.org/10.1080/10635150390235520.

72. Ronquist F, Teslenko M, van der Mark P, Ayres DL, Darling A, Höhna D, Larget B, Liu L, Suchard MA, Huelsenbeck JP. MrBayes 3.2: efficient Bayesian phylogenetic inference and model choice across a large model space. Syst Biol. 2012;61:539-42. https://doi.org/10.1093/sysbio/sys029.

\section{Publisher's Note}

Springer Nature remains neutral with regard to jurisdictional claims in published maps and institutional affiliations.

Ready to submit your research? Choose BMC and benefit from:

- fast, convenient online submission

- thorough peer review by experienced researchers in your field

- rapid publication on acceptance

- support for research data, including large and complex data types

- gold Open Access which fosters wider collaboration and increased citations

- maximum visibility for your research: over $100 \mathrm{M}$ website views per year

At $\mathrm{BMC}$, research is always in progress.

Learn more biomedcentral.com/submissions 